\title{
Contributions of Individual Layer 6 Pyramidal Neurons to Local Circuitry in Macaque Primary Visual Cortex
}

\author{
Anne K. Wiser and Edward M. Callaway \\ Neuroscience Program and Department of Physiology, University of Colorado School of Medicine, \\ Denver, Colorado 8026 ?
}

We have studied the contributions of individual layer 6 pyramidal neurons in macaque primary visual cortex to local cortical circuitry by intracellular labeling and analysis of the morphologies of 58 neurons. These neurons are separated based on the laminar specificity of axonal and dendritic arbors into two classes, class I and class II, and into several types within these classes. Class I neurons project axons heavily and predominantly to layer $4 \mathrm{C}$, whereas class II neurons have axonal projections primarily to layers other than $4 \mathrm{C}$. Only 16 of the 58 neurons in our sample (28\%) project to the white matter. Class I projection neurons are found at the top and bottom of layer 6 , suggesting that they project to the lateral geniculate nucleus, whereas class II projection neurons are located in the middle of

The brain is a highly organized structure the function of which is dependent on the way in which its neurons are interconnected. The visual system is no exception to this rule. Thus, an important step toward understanding how the visual cortex mediates visual perception is to know the precise anatomy of neuronal projections. Although past studies have revealed much of the detailed local circuitry of arca V1 in the macaque monkey (Lund, 1973; Lund and Boothe, 1975; Lund et al., 1977; Blasdel et al., 1985; Fitzpatrick et al., 1985; Valverde, 1985; Katz et al., 1989; Lachica et al., 1992; Anderson et al., 1993; Yoshioka et al., 1994), our understanding of the contributions of individual neurons to these circuits is limited.

Here we focus on understanding the contributions of individual layer 6 pyramidal neurons in macaque V1 to visual processing. These neurons are of particular interest because they are in the unique position of being able to sample inputs both from the neurons that provide input to $\mathrm{V} 1$ (geniculocortical afferents) (Lund, 1988) and from those that provide output from V1 to extrastriate cortical areas (Blasdel et al., 1985; Yoshioka et al., 1994). They, in turn, project axons back to the lateral geniculate nucleus (LGN) (Fitzpatrick et al., 1994) and also locally within V1 (Blasdel et al., 1985; Yoshioka et al., 1994). Investigations of the function of layer 6 neurons in cat primary visual cortex suggest

Received Aug. 30, 1995; revised Ian. 16, 1996; accepted Jan. 22, 1996.

This work was supported by National Institutes of Health Grant EY10742, the Esther A. and Joseph Klingenstein Fund, and National Institutes of Health Training Grant T32 HD07408 (A.K.W.). We thank Janet Lieber for expert technical assistance; Dr. Carl Lupica for sharing his equipment, time, and expertise; Dr. Joseph Callaway, Dr. Carl Lupica, and Atomu Sawatari for assistance labeling neurons; and Lori Greiner for assistance with animals.

Correspondence should be addressed to Ed Callaway, MNL-C, The Salk Institute, 10010 North Torrey Pines Road, La Jolla, CA 92037.

Dr. Wiser's and Dr. Callaway's present address: Molecular Neurobiology Laboratory, The Salk Institute for Biological Studies, La Jolla, CA 92037.

Copyright (C) 1996 Society for Neuroscience 0270-6474/96/162724-16\$05.00/0 layer 6, suggesting that they project to the claustrum. The different types of class I neurons are distinguished from one another based on the sublaminar specificity of their axonal and dendritic arbors within layer 4 , where they are biased toward compartments dominated by input from different functional streams. They are also distinct in their distributions within the depth of layer 6 . The distinctive characteristics of the neuronal types we have identified suggest that each receives input from different sources and projects to a set of targets that is functionally appropriate. Thus, each type is likely to contribute uniquely to computations within $\mathrm{V} 1$ and extrinsically.

Key words: macaque; visual cortex; V1; area 17; striate cortex; local circuits; biocytin; cytochrome-oxidase

that they contribute importantly to the generation of novel neuronal response properties that emerge in this area (Sherk and LeVay, 1983; Bolz and Gilbert, 1986; Sillito et al., 1994). However, in view of the numerous differences in the organization of primate and feline visual systems and our limited understanding of the anatomy of individual layer 6 neurons in the macaque, it is not clear how these studics might rclatc to laycr 6 function in primates.

A number of studies have provided important insight into the contributions of layer 6 neurons to local and extrinsic circuits in the macaque. Studies based on small extracellular injections of anterograde and retrograde tracers reveal that layer 6 neurons project local axon collaterals to all of the cortical layers (Blasdel et al., 1985; Yoshioka et al., 1994). The resolution of whether these projections arise from a uniform population of neurons that each project axons throughout the cortical depth or from distinct types that each project to only a particular subset of the layers requires knowledge about the anatomy of individual neurons. Some of the earliest studies of layer 6 neurons indicated that they are in fact a diverse population. Golgi studies in adult macaque monkeys (Lund, 1973; Lund and Boothe, 1975) revealed at least five types, each with a distinct pattern of dendritic laminar specificity; axonal arbors could be visualized for only two types. Golgi studies of neonatal material resulted in better axonal labeling and the identification of eight neuronal types (Lund et al., 1977). It is not certain, however, whether the axonal projection patterns observed in neonatal animals persist postnatally, nor whether the neuronal types identified by Golgi staining represent all of the types that are present. Intracellular staining of a large population of layer 6 neurons in postnatal animals can help to resolve these issues.

Insight into the possible functional roles of the different types of layer 6 neurons also requires more detailed information about 
each type. For example, retrograde labeling studies reveal that corticogeniculate neurons are found only at the top and bottom of layer 6 (not in the middle), with those projecting to magnocellular layers being found exclusively at the bottom (Fitzpatrick et al., 1994). Also, in the cat claustral projecting neurons are found only in the middle of layer 6 (LeVay and Sherk, 1981). These observations suggest that different neuronal types might be found only at particular depths in layer 6. Information about the depth distribution of various neuronal types, therefore, could provide insight into their likely extrinsic targets. The results of Fitzpatrick et al. (1994) also suggested that only a small percentage of layer 6 cells projects to the LGN. Knowledge of the percentage of layer 6 neurons that project to the white matter and their likely targets might provide support for this finding. Also, some neuronal types might lack extrinsic projections altogether, and it would be informative to identify any such types.

We therefore intracellularly labeled and reconstructed layer 6 pyramidal neurons in macaque V1 to obtain a more detailed description of visual cortical circuitry, with the eventual goal of understanding how each type contributes to the emergence of the specific visual response properties of the neurons to which it connects. Our primary aims were as follows: (1) to identify the various types of layer 6 pyramidal neuron; (2) to reveal the laminar specificity and lateral extent of the axonal and dendritic arbors of each type; (3) to determine whether particular cell types are found at particular depths in layer 6; and (4) to determine which cell types contribute input to an extrinsic target (i.e., the LGN or claustrum).

We have labeled and analyzed the axonal and dendritic arbors of 58 layer 6 pyramidal neurons. The diversity in laminar specificity of dendritic and axonal projections of these layer 6 cells leads to a separation into two classes of neurons, and several types within each class. Each neuronal type is distinctive in terms of the following: (1) its patterns of dendritic and axonal arborization; (2) its distribution within the depth of layer $6 ;(3)$ whether a subset of the neurons projects to the white matter; and (4) the depth distribution of the projection neurons (if any). We propose that each cell type serves distinct functions in the shaping of receptive fields within V1 and discuss the possibility that, in the monkey, these neurons play similar roles to those in the cat.

\section{MATERIALS AND METHODS}

Individual neurons in the primary visual cortex of macaque monkeys were intracellularly labeled in living brain slices and their axonal and dendritic arbors analyzed as described below. We labeled and analyzed 58 layer 6 pyramidal neurons from eight macaque monkeys (Macaca radiata) of both sexes: B8, B11, B12, B13, B14, B16, B17, and B19. The ages of the animals ranged from 2 to 9 months postnatal. We used young animals because it is much more difficult to obtain whole-cell recordings in slices prepared from older animals. The age of each animal and the number of cells it contributed to our sample are indicated in Table 1. Neurons of each type were similar in both axonal and dendritic morphology, regardless of the ages of the animals from which they were sampled. Additional neurons labeled in other layers are not described here. Examples of biocytin labeled cells are shown in the photographs in Figure 1 and after camera lucida reconstruction in Figures 2-9.

Preparation of cortical slices. We prepared $400-\mu \mathrm{m}$-thick coronal slices from striate cortex using methods essentially identical to those described previously for cats (Katz, 1987; Callaway and Katz, 1992) and monkeys (Katz et al., 1989). Briefly, animals were deeply anesthetized with sodium pentobarbital $(40-60 \mathrm{mg} / \mathrm{kg}$, i.p.), and a large craniotomy was made to expose the striate cortex. The dura was removed, and a large portion of striate cortex $(-2 \mathrm{~cm}$ wide and $2.5 \mathrm{~cm}$ long) was cut free with a scalpel and removed. This tissue was then placed in chilled $\left(\sim 2^{\circ} \mathrm{C}\right)$, oxygenated artificial CSF (ACSF; composition in mM: $\mathrm{NaCl} 124, \mathrm{KCl} 5, \mathrm{KH}_{2} \mathrm{PO}_{4} 1.25$, $\mathrm{MgSO}_{4} 2, \mathrm{CaCl}_{2} 3, \mathrm{NaHCO}_{3} 26, d$-glucose 10 , and kynurenic acid 1, pH
7.4). The animal was overdosed with an additional dose of sodium pentobarbital $(100 \mathrm{mg} / \mathrm{kg}$, i.p.) after removal of the cortex. After chilling for $\sim 1 \mathrm{~min}$, the cortical tissue was placed on filter paper saturated with ACSF, the pia was removed with fine forceps, and the tissue was cut into two blocks, each $\sim 6-8 \mathrm{~mm}$ wide and $2 \mathrm{~cm}$ long, that were then sliced coronally to a thickness of $400 \mu \mathrm{m}$ using a specialized "egg slicer"-like devicc (Katz, 1987). This procedure yielded $>100$ slices of whicl $40-60$ were typically stored in oxygenated interface chambers warmed to $34^{\circ} \mathrm{C}$ for later intracellular filling. These slices originated from positions distributed over nearly the entire exposed surface of area Vl-anteriorly from the V1/V2 border to the occipital pole posteriorly, and mediolaterally from the midline to $\sim 2.5 \mathrm{~cm}$ laterally. Thus, labeled neurons in our sample are not localized to any particular representation of the visual field, with the exception that regions corresponding to tissue folded beneath the exposed surface of the brain were not sampled.

Intracellular labeling. After incubating in the interface chamber for at least $1 \mathrm{hr}$, slices were transferred to a recording chamber where they were submerged in warm $\left(34^{\circ} \mathrm{C}\right)$, oxygenated ACSF circulating at a rate of $\sim 2$ $\mathrm{ml} / \mathrm{min}$. Whole-cell recordings were obtained in either voltage-clamp or current-clamp mode using methods similar to those described previously (Blanton et al., 1989). The electrodes used had resistances of 5-15 M $\Omega$ and were filled with the following solution: $130 \mathrm{~mm} \mathrm{~K}$-gluconate, $1 \mathrm{~mm}$ EGTA, $2 \mathrm{~mm} \mathrm{MgCl}_{2}, 0.5 \mathrm{mM} \mathrm{CaCl}_{2}, 2.54 \mathrm{~mm}$ ATP, $10 \mathrm{~mm}$ HEPES, and $2 \%$ biocytin (Sigma, St. Louis, MO), pH 7.3. After a whole-cell recording was obtained, biocytin was iontophoresed into the cell with positive current pulses of $0.3 \mathrm{nA}$, and $33 \mathrm{mS}$ duration at $10 \mathrm{~Hz}$. Cells were typically filled for at least $10 \mathrm{~min}$, and this procedure invariably resulted in complete filling of the axonal and dendritic arbors (see Fig. 1). Occasionally, recordings were lost after shorter periods, but the filling was often excellent despite the shorter filling duration. Only neurons in which the entire dendritic and axonal arbor could be clearly visualized after staining are included in our analyses. Electrode penetrations into the slice were spaced such that labeled neurons would be at least $1 \mathrm{~mm}$ apart laterally. After several neurons in a slice were labeled, it was returned to the interface holding chamber for $\sim 2-6 \mathrm{hr}$. This postincubation procedure resulted in removal of nonspecific labeling at the locations of electrode penetrations, which would otherwise obscure the processes of specifically labeled neurons. After postincubation, slices were fixed by immersion in $4 \%$ paraformaldehyde in $0.1 \mathrm{M}$ phosphate buffer for $12-14 \mathrm{hr}$. The short fixation time was crucial for obtaining good quality $\mathrm{CO}$ staining; shorter fixation times did not result in adequate tissue preservation.

Tissue processing. Following fixation, slices were sunk in $30 \%$ sucrose in $0.1 \mathrm{M}$ phosphate buffer and then sectioned on a freezing microtome to a thickness of $50-100 \mu \mathrm{m}$. Sections were rinsed three times in PBS and then stained for $\mathrm{CO}$ by incubation in a solution containing $30 \mathrm{mg}$ of cytochrome $c, 20 \mathrm{mg}$ of catalase, and $50 \mathrm{mg}$ of diaminobenzidine (DAB; all from Sigma) per $100 \mathrm{ml}$ of PBS, for $2-4 \mathrm{hr}$ at $40-50^{\circ} \mathrm{C}$ (Horton, 1984). Sections were rinsed again three times in PBS and then incubated in $10 \%$ methanol and $3 \% \mathrm{H}_{2} \mathrm{O}_{2}$ in PBS for $30 \mathrm{~min}$. This step inactivates endogenous peroxidases commonly associated with blood vessels in the nonperfused brain tissue. The sections were rinsed again five times in PBS and then incubated in a horseradish peroxidase (HRP)-conjugated avidin-biotin complex (ABC; Peroxidase Standard Kit, Vector Laboratories, Burlingame, $\mathrm{C} \Lambda$ ), prepared at the standard concentration in PBS and $0.75 \%$ Triton $X-100$, for $2 \mathrm{hr}$. Sections were rinsed three times in PBS, submerged in $0.1 \%$ glutaraldehyde in PBS for 4 min (to reduce background staining), and then rinsed five times in PBS. Finally, the intracellularly injected biocytin was revealed by reacting the sections in a solution containing $50 \mathrm{mg}$ of $\mathrm{DAB}, 2.8 \mathrm{ml}$ of $1 \% \mathrm{CoCl}_{2}, 2.0 \mathrm{ml}$ of $1 \%$ nickel ammonium sulfate, and $10 \mu \mathrm{l}$ of $30 \% \mathrm{H}_{2} \mathrm{O}_{2}$ per $100 \mathrm{ml}$ of PBS for 5-15 min. This procedure resulted in a dense, black reaction product in labeled neurons, against the reddish brown reaction product from the $\mathrm{CO}$ stain (see Fig. 1).

Determination of laminar boundaries. Laminar boundaries were defined based on the pattern of $\mathrm{CO}$ staining in each section, as indicated in Figure 1. The criteria used were similar to those of Lund $(1987,1988)$. The most distinct laminar feature in the $\mathrm{CO}$-stained tissue is layer $4 \mathrm{C}$, which is the most densely stained region in the middle of the gray matter. The subdivisions of this layer, $4 \mathrm{C} \alpha$ and $4 \mathrm{C} \beta$, are not distinguished by the $\mathrm{CO}$ stain and, therefore, we define the upper half of layer $4 \mathrm{C}$ as $4 \mathrm{C} \alpha$ and the lower half as $4 \mathrm{C} \beta$. Superficial to layer $4 \mathrm{C}$ is a lightly stained zone, layer $4 \mathrm{~B}$, and a thin, darker-staining band, layer $4 \mathrm{~A}$. Layer 1 is a thin, CO-dense zone just beneath the pial surface. We refer to the region between layer $4 \mathrm{~A}$ and layer 1 as layer $2 / 3$ and further subdivide this region into layers 2/3A (the upper two-thirds) and 3B (the lower third). Layer 5 is a lightly 
stained zone just below layer $4 \mathrm{C}$, and it is separated from the white matter by the darker-staining layer 6 . Layer 5 is divided into an upper region, layer 5A (the upper third of layer 5), and a lower region, layer 5B (the lower two-thirds of layer 5 ). The border between layer 6 and the white matter is marked by a sharp decrease in the intensity of $\mathrm{CO}$ staining. $\mathrm{CO}$ staining also distinguishes the blob and interblob regions in layer $2 / 3$.

Analyses of labeled neurons. Stained sections were scanned at $100 \times$ magnification [10X, 0.5 numerical aperture (NA) objective] to locate labeled neurons, and suitably labeled cells were identified. Such cells were labeled well enough that even the most distal axonal processes could easily be seen with the $10 \times$ objective (see Fig. 1). Each neuron was then carefully scrutinized at variable magnification to determine in detail its patterns of axonal and dendritic arborization and its relation to the cortical layers and $\mathrm{CO}$ blob and interblob regions of layer $2 / 3$. Detailed camera lucida reconstructions of axonal arbors were made using a $60 \times$ or $63 \times$ (1.4 NA) oil immersion objective. Crude dendritic drawings were made using a $10 \times$ or $20 \times$ objective; the thickness of dendrites and other details such as dendritic spines are not indicated in these drawings, but all dendritic branches are shown. Camera lucida drawings were photographed with a large-format camera, and photographic prints were made from the negatives. The prints were then scanned electronically using a PC-based computer system. Scale bars and hand-drawn lines indicating laminar and blob/interblob borders were replaced with computer-drawn lines at their original positions on the scanned images, using the program CorelDraw.

Although both en passant synaptic boutons and side-spine boutons could be clearly visualized in all of the labeled neurons, we have not reconstructed their distributions or analyzed them quantitatively. We do note, however, that synaptic boutons are present on all axonal branches, with the exception of the thick, unbranched recurrent collaterals rising up from class I neurons. Thus, to a rough approximation, the density of axonal branches is representative of the strength of a projection, and we refer to this characteristic as our primary determinant of projection strength.

Each neuron was also investigated to determine whether its main descending axon projected to the white matter. When the axon could be seen entering the white matter, the cell was scored as a projection neuron. Neurons were scored as nonprojecting only if the descending axon clearly ended within the plane of the slice. In no case was the determination of projection to the white matter ambiguous (i.e., we did not ever encounter descending axons leaving the plane of the slice before we could determine whether they projected to the white matter).

We calculated the depth at which the cell body of each neuron lies in layer 6 by the following: drawing with the camera lucida the bottom and top borders of layer 6 and the position of the cell body; measuring the distance between the base of the cell body and the layer $5 / 6$ border; dividing this distance by the whole depth of layer 6 ; and multiplying this ratio by 100 . We defined "superficial" as a depth $\leq 40 \%$, "middle" as between 40 and $60 \%$, and "deep" as $\geq 60 \%$.

\section{RESULTS}

We have labeled and analyzed 58 pyramidal neurons with cell bodies in layer 6 . Photographs indicating the quality of neuronal labeling that was observed for the neurons included in our analyses are shown in Figure 1. Note that even with the low-power $10 \times$ objective used to make the photographs in Figure $1 a-c$, axonal branches are clearly visible. These branches are actually even more obvious than can be shown with these black and white photographs because of the contrasting color of the $\mathrm{CO}$ versus biocytin labeling. Also, many out-of-focus branches can only be seen by changing the focal plane. In some cases, there is a "haze" of labeling surrounding the cell body, which presumably results from leakage during iontophoresis and/or from pressure ejection of dye before obtaining whole-cell recordings (Fig. 1a). Despite this haze, observation with a higher-power objective and stoppeddown condenser aperture allows clear visualization of the axon emerging from the base of the cell body, unequivocally linking the reconstructed axonal arbor to the parent cell.

We have distinguished two major classes of layer 6 pyramidal neurons, which we designated as class I and class II. These classes were defined based on the laminar specificity of axonal and dendritic arbors. Class I cells $(n=28)$ have dense axonal projections primarily within layer $4 \mathrm{C}$ (Fig. $1 a-c$ ), whereas class II cells $(n=30)$ have more widespread axonal projections. In addition, class I neurons lack dendritic branches in layer 5B (Fig. 1a-c), whereas class II cells do have dendritic branches in layer 5B (Fig. $1 d$ ). We have subdivided class I neurons into several types, again according to the laminar specificity of their processes. Class I was divided into five types: $\mathrm{I} \alpha(n=6), \mathrm{I} \beta(n=8), \mathrm{I} \beta \mathrm{A}(n=7), \operatorname{Im}(n$ $=4)$, and IC $(n=3)$. Although the patterns of dendritic and axonal arborization of class II neurons are quite diverse, we are not able to separate most of them into distinct groups. Only one type stands out: a type we have called IIB $(n=6)$. We will refer to the class II cells that do not belong to the type IIB as type IIA.

\section{Class I neurons}

Twenty eight of the 58 layer 6 pyramidal cells in our sample were classified as class I neurons. As shown in Figures 2-6, class I cells project heavily and predominantly to layer $4 \mathrm{C}$. Each type of class I neuron is distinct in terms of the following: (1) the sublaminar specificity of axonal arbors within layer $4 \mathrm{C}$; (2) the pattern of dendritic arborization; (3) the distribution of neurons within the depth of layer 6 ; and (4) the depth distribution of the neurons that project out of V1, if any.

\section{Type I $\alpha$}

Out of the 28 class I cells, 6 have dense axonal arbors predominantly within layer $4 \mathrm{C} \alpha$ and are therefore defined as type $\mathrm{I} \alpha$ cells (Figs. 1a,2). The axonal projections of these neurons are quite focused in $4 \mathrm{C} \alpha$, with occasional branches dropping into $4 \mathrm{C} \beta$ or extending into layer $4 \mathrm{~B}$; but no branching is observed in these layers. Most (5/6) also have weak axonal projections within layer 6 (Fig. 2b). Axonal arbors extend 1-2 mm laterally within layer $4 \mathrm{C} \alpha$. These arbors appear to have a uniform distribution without any signs of periodic clustering (Fig. $2 a, b)$. None of the six type I $\alpha$ neurons projects to the white matter (Fig. $2 a, b$, Table 2). Type I $\alpha$ neurons have numerous basal dendrites in layer 6 and apical dendritic branches in layers 6 and $4 \mathrm{C} \alpha$; two of them also have dendritic branches in layer 5A (Fig. 2a). Four out of six have their somata in the middle of layer 6 (Fig. $2 a, b$ ), whereas the other two are somewhat deeper (Fig. 10, Table 2).

\section{Type I $\beta$}

Our sample includes eight type I $\beta$ neurons (Fig. 3). These cells have axonal arbors predominantly in layer $4 \mathrm{C} \beta$ (Fig. $3 a, b$ ), and half $(4 / 8)$ also send weaker projections to their own layer, layer 6 (Fig. $3 b$ ). Although some axonal branches can extend into the bottom of layer $4 \mathrm{C} \alpha$ (Fig. $3 b$ ), they clearly do not extend to the top of layer $4 \mathrm{C}$. These cells have a more limited lateral axonal spread than the type I $\alpha$ neurons; they never extend more than 1 $\mathrm{mm}$ laterally and can be as narrow as $360 \mu \mathrm{m}$. These arbors also do not form periodic clusters. Both apical and basal dendritic branches lie in layer 6, and the apical dendrite also branches in layers $5 \mathrm{~A}$ and $4 \mathrm{C} \beta$ (Fig. 3). In two cases, the apical dendrite extends up to layer $4 \mathrm{~A}$. Type I $\beta$ neurons can be found throughout the depth of layer 6 (Figs. 10, 11, Table 2), and three out of eight project to the white matter (Table 2). None of four neurons with somata near the middle of layer 6 (depths of $35-75 \%$ ) projects to the white matter, whereas three of four located more superficially or deeper do project to the white matter. Thus, there appears to be a tendency for the projecting cells to be situated at the edges of layer 6 , but not in the middle (see Fig. 11). 


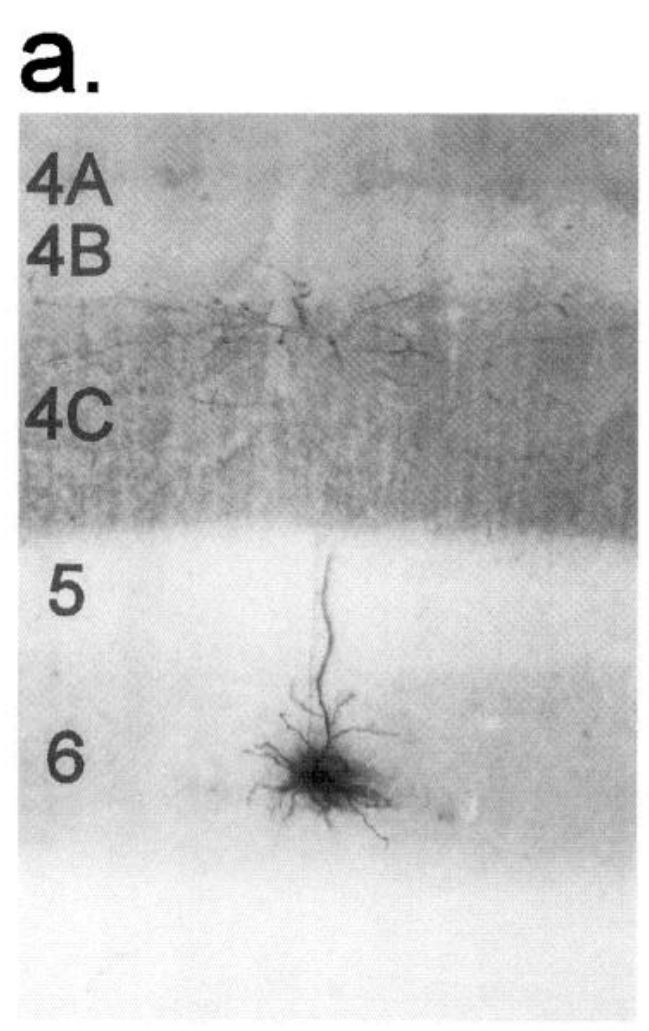

b.
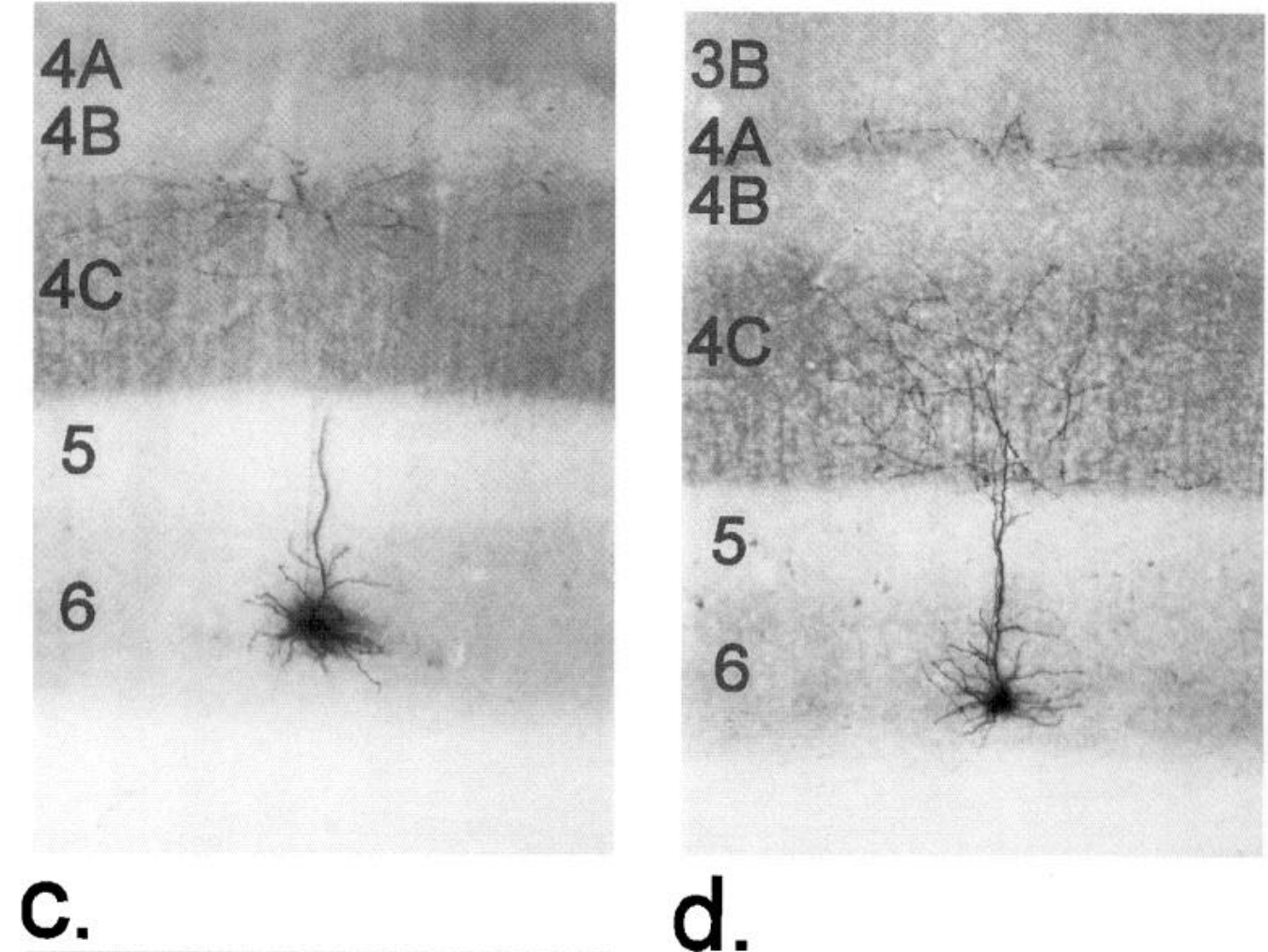

d.
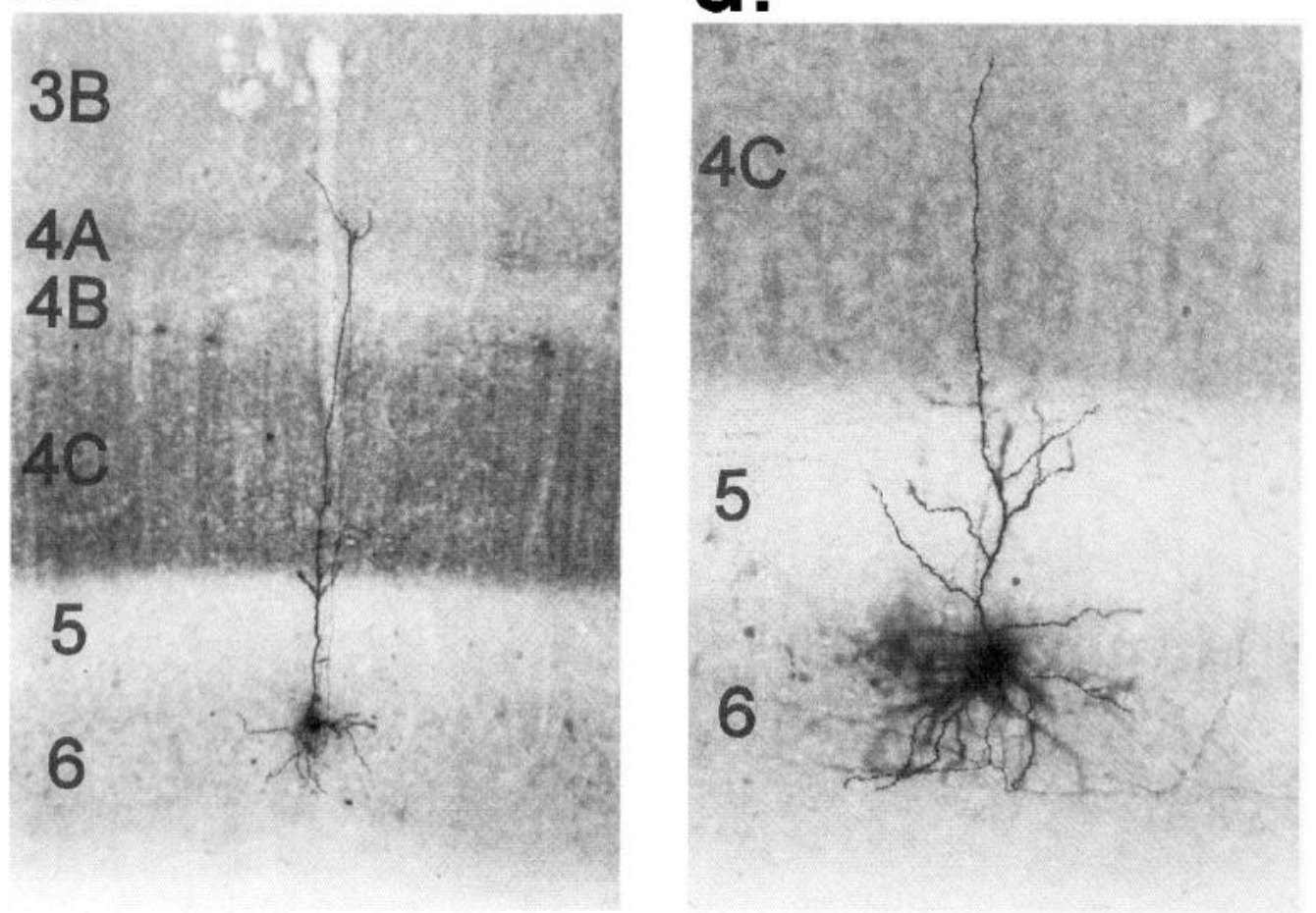

Figure 1. Photographs of processed tissue sections containing biocytin-filled layer 6 neurons. The cortical layers revealed by cytochrome oxidase staining are identified at the left side of each photograph. The dendritic arbor appears thicker than the axonal arbor. $a$ illustrates a type I $\alpha$ neuron. The basal dendrites are restricted to layer 6 . The apical dendrite has a few branches in layer 6 , ascends unbranched in layer 5 where it leaves the plane of this section, and then reappears and branches at the top of layer $4 C(4 \mathrm{C} \alpha)$. The axon branches in layer 6 , ascends unbranched in layer 5 where it also leaves the plain of this section to reappear along with numerous branches in layer $4 \mathrm{C} \alpha(4 C)$. A reconstruction of this neuron is shown in Figure $2 b$. Shown in $b$ is a type IC neuron with its cell body in deep layer 6 . The apical dendrite of this cell has a few branches in layers 6 and $5 \mathrm{~A}(5)$ and leaves the plain of this section in $4 \mathrm{C} \beta(4 \mathrm{C})$. The axon has a few branches in layer 6 , and the main descending axon extends into the white matter. Ascending axonal collaterals branch throughout layer $4 C$ and in layer $4 A$. $c$, Photograph of a type I $\beta$ A neuron. The cell body is in superficial layer 6 . The basal dendrites are restricted to layer 6 . The apical dendrite branches in layers $5 \mathrm{~A}(5), 4 \mathrm{C} \beta(4 C)$, and $4 A$; it does not extend above layer $3 B$. A majority of axonal branches are present in other sections of the slice where this neuron was labeled, but branches in layer $4 \mathrm{C} \beta(4 C)$ are visible. The camera lucida reconstruction of this neuron is shown in Figure $4 a$. $d$, A typical type IIA neuron with its apical dendrite branching throughout layer 5 and extending unbranched into layer $4 C$. 
Figure 2. Camera lucida reconstructions of type I $\alpha$ neurons. Axonal arbors (fine lines) are illustrated in their actual positions and originate from the cell body as indicated (filled figures). Dendrites (in bold) are shown at their actual height and size but are offset to the side to avoid obscuring the axonal arbor. Horizontal lines indicate the laminar boundaries of the cortical layers identified by labels on the left side. Slanted lines (to the right of $b$ ) indicate laminar boundaries as the tissue curves. The cell bodies of the neurons shown in $a$ and $b$ are in the middle of layer 6 . Both neurons project axonal branches predominantly to layer $4 C$ and, hence, belong to class I. More specifically, they project to layer $4 \mathrm{C} \alpha$ and, therefore, belong to the type I $\alpha$ (see Results). The neuron shown in $b$ also projects to its layer of origin (layer 6 ). As illustrated in $a$ and $b$, type I $\alpha$ cells do not project to the white matter. The apical dendrites of type $\mathrm{I} \alpha$ cells branch in layer $4 C \alpha(4 C)$. The neuron illustrated in $a$ also has dendritic branches in layer $5 \mathrm{~A} \mathrm{(5)}$. The basal dendrites and additional apical dendritic branches are in layer 6 . A photograph of the neuron illustrated in $b$ is shown in Figure $1 a$. Scale bars, $200 \mu \mathrm{m}$.

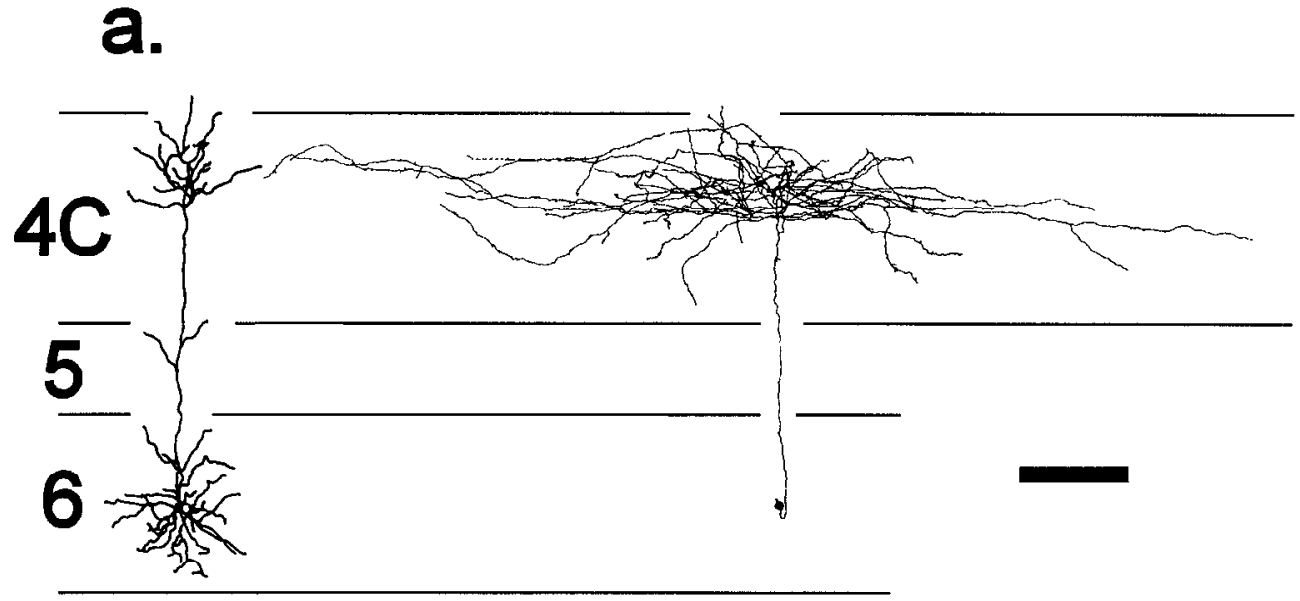

b.

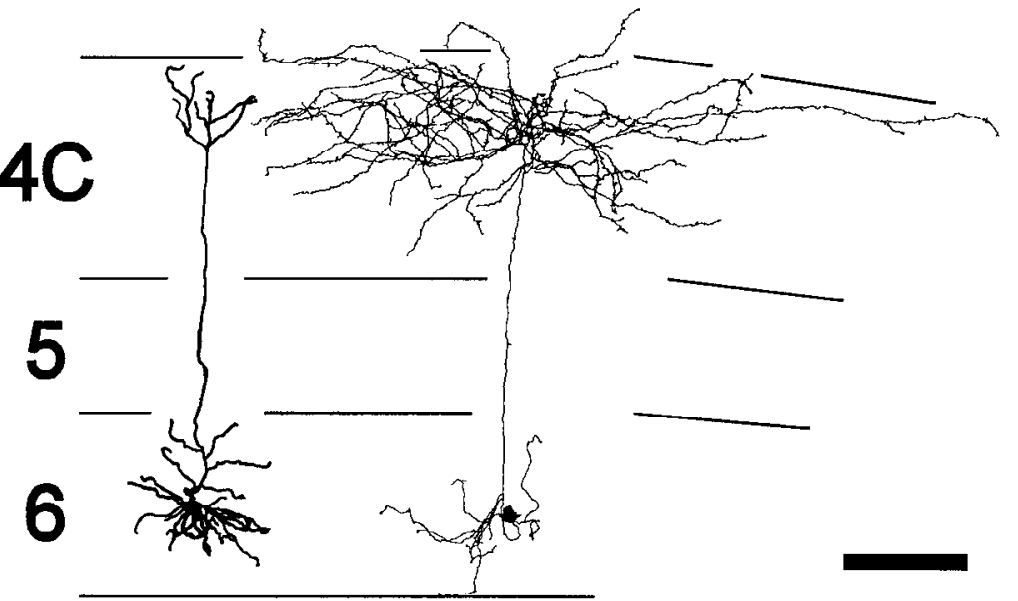

\section{Type I $\beta A$}

We labeled seven type I $\beta$ A cells (Figs. $1 c, 4$ ). These cells have axonal arbors similar to type $\mathrm{I} \beta$ cells, except that they also project an ascending collateral to layer $4 \mathrm{~A}$ (and sometimes to layer $2 / 3,3$ of 6 cells) where it branches (Fig. $4 b$ ). The lateral axonal spread of $\mathrm{I} \beta \mathrm{A}$ neurons in layer $4 \mathrm{C}$ is similar to the type $\mathrm{I} \beta$, ranging from $\sim 300 \mu \mathrm{m}$ to $1.1 \mathrm{~mm}$. In layer $4 \mathrm{~A}$, it can be as narrow as $170 \mu \mathrm{m}$ and as wide as $1.5 \mathrm{~mm}$ (Fig. $4 b$ ).

The dendritic pattern of the type $\mathrm{I} \beta \mathrm{A}$ cells is similar to the type $I \beta$, except that the apical dendrite of the type I $\beta A$ cells in our sample always extends to layer $4 \mathrm{~A}$ (and occasionally to layer $3 \mathrm{~B}$ ) where it branches. All type I $\beta$ A cells have somata in upper layer 6 (Figs. 10, 11, Table 2), further distinguishing them from the type $\mathrm{I} \beta$ cells. The three type I $\beta$ A cells located most superficially in layer 6 project to the white matter, whereas the four with somata closer to the middle of layer 6 do not (Fig. 11, Table 2).

\section{Type Im}

We labeled 4 class I cells that, instead of having axonal arbors focused in layer $4 \mathrm{C} \alpha$ or $4 \mathrm{C} \beta$, project heavily to the middle of layer $4 \mathrm{C}$, with few branches at the edges of the layer (Fig. 5). We called these cells type Im. The lateral spread of their axons is compara- ble in extent with type I $\beta$ and I $\beta$ A cells, but less variable (range, $560-775 \mu \mathrm{m})$. The axonal arbors lack any signs of periodic clustering. Unlike many class I cells, none of the type Im neurons in our sample has axonal branches in their own layer.

All type Im cells have apical and basal dendritic branches in layer 6 , and apical dendrites that extend into layer $4 \mathrm{C}$ and branch in layer $5 \Lambda$. Two out of four cells also have apical dendritic branches in the middle of $4 \mathrm{C}$ (Fig. 5). The apical dendrite can extend as high as layer 4B (Fig. 5a). Most type Im cells (3/4) have somata in the middle of layer 6 (one was slightly above the middle, Fig. 10, Table 2), and none projects to the white matter (Table 2).

\section{Type IC}

Our sample includes three type IC neurons (Figs. $1 b, 6$ ). These cells project axons predominantly to layer $4 \mathrm{C}$ and throughout the depth of this layer without any preference for any subdivision of $4 \mathrm{C}$ (Fig. $6 a, b$ ). Like type I $\beta A$ cells, they also project axons to layer $4 \mathrm{~A}$ (Fig. $6 b$ ) and sometimes 3B (Fig. 6a). The lateral spread of axonal arbors is centered around $1 \mathrm{~mm}$ in a tight range: $900 \mu \mathrm{m}$ to $1.1 \mathrm{~mm}$ with no indications of periodic clusters. Type IC cells have basal dendrites in layer 6 and their apical dendrite branches in layers 6 and $5 \mathrm{~A}$, and occasionally in layer $4 \mathrm{C}$ or $4 \mathrm{~A}$. Type IC 
a.

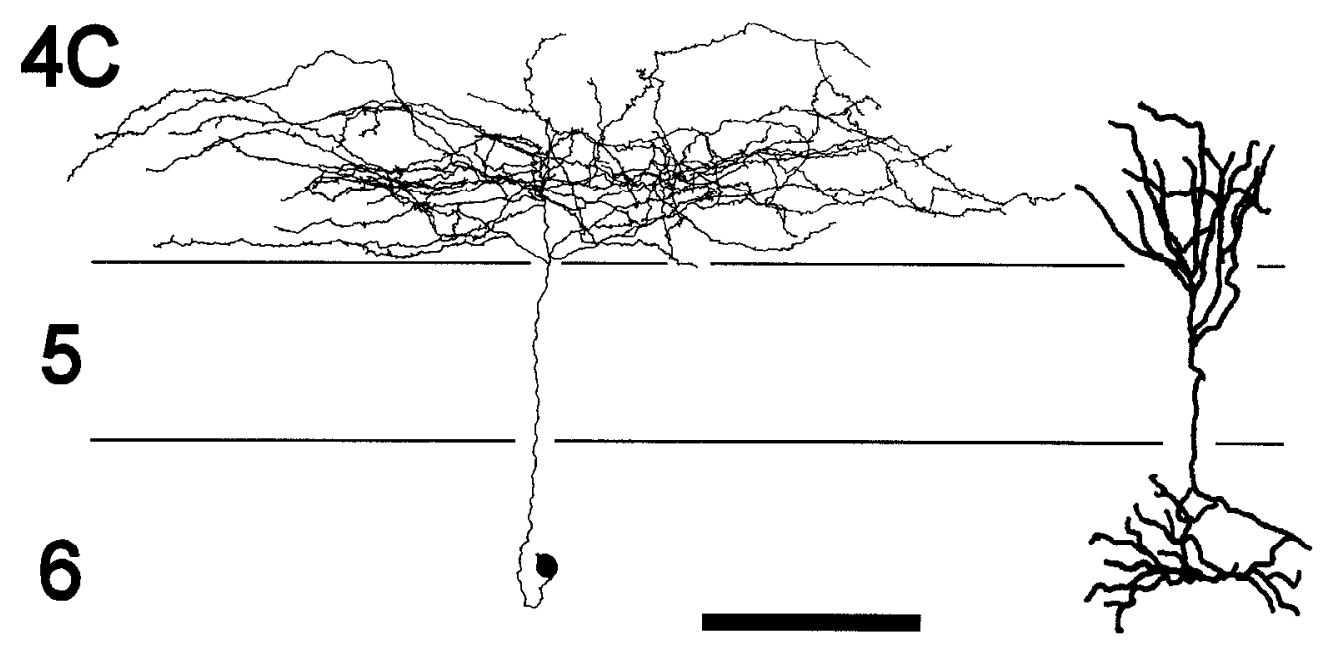

b.

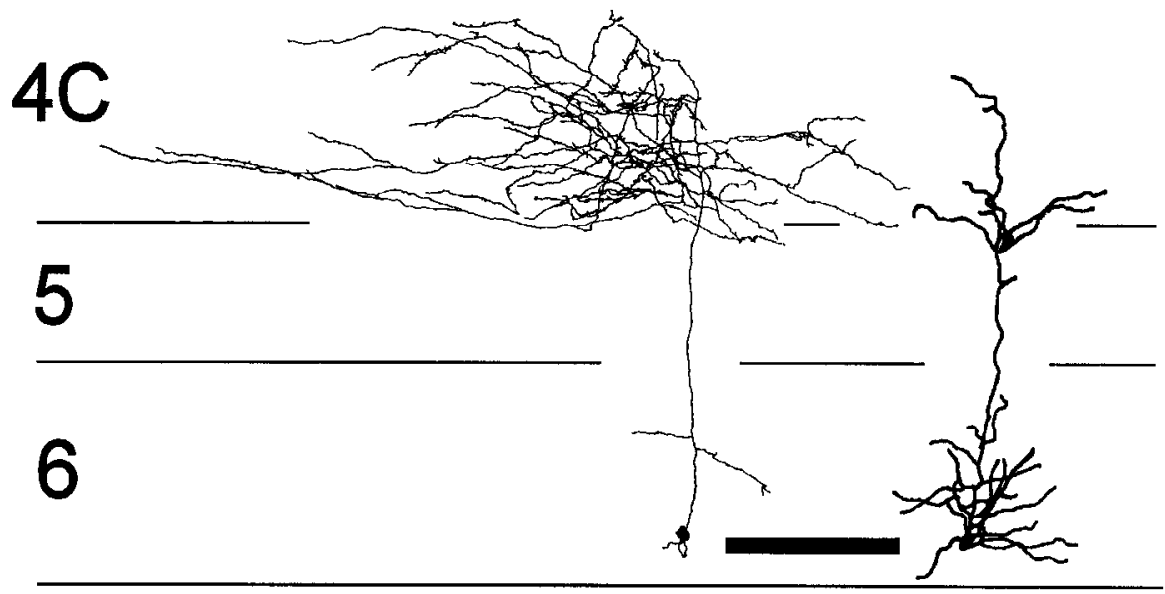

Figure 3. Camera lucida reconstructions of type I $\beta$ neurons. Both neurons $(a, b)$ project axonal branches predominantly to layer $4 \mathrm{C} \beta(4 C)$ and, therefore, belong to the type $\mathrm{I} \beta$ (see $\mathrm{Re}$ sults). The neuron shown in $b$ also has weak axonal projections to layer 6 . The neuron shown in $a$ has its cell body in the middle of layer 6 . The soma of the cell shown in $b$ is in deep layer 6 . These two neurons do not project to the white matter, but others of the same type do. Dendritic branches of both cells arborize in laycrs $6,5 \mathrm{~A}(5)$, and $4 \mathrm{C} \beta(4 C)$. See legend of Figure 2 for conventions. Scale bars, $200 \mu \mathrm{m}$. cells are distinguished further from type $\mathrm{I} \beta$ and $\mathrm{I} \beta \mathrm{A}$ cells in that all are found deep in layer 6 (Fig. 10) and project to the white matter (Table 2).

\section{Relationship of class I neurons to layer 5}

Overall, only 3 of 28 class I cells have dendritic branches in layer $5 \mathrm{~B}$. One type I $\beta$ neuron has three dendritic branches in layer $5 \mathrm{~B}$, one type I $\beta A$ cell has two, and another has one branch in this sublayer (Fig. $4 b$ ). This contrasts sharply with class II cells (see below).

\section{Class II neurons}

Class II neurons lack a preference of axonal arbors for the main LGN recipient layer, layer 4C (Figs. 7-9). Also, these neurons always have dendritic branches in layer 5B (Figs. 1d, 7-9). Thirty out of 58 layer 6 cells fall into this class. Most class II cells (24/30) project axons to layer $2 / 3$, but none has an obvious preference for
CO blobs or interblobs. There is no apparent difference in the density of axon collaterals or branches in blobs versus interblobs.

\section{Type $I I A$}

Type IIA cells $(n=24)$ are the most diverse type of layer 6 neuron. Some have relatively sparse axonal arbors that form branches throughout the cortical depth (Fig. 7a,b). Most, however, have more extensive axonal arbors within the infragranular layers (Fig. $8 a, b$ ). We do not separate these into distinct types, however, because they appear to represent extremes along a continuum. Some type IIA cells have lateral axonal branches in layers 6 and 5, and also project to the superficial layers (Fig. 8b); others project laterally (up to $2.55 \mathrm{~mm}$ ) within layer 6 and sometimes 5 , but do not project into more superficial layers (Fig. $8 a$ ). Long-distance collaterals in layer 6 can form periodic clusters of axonal branches that are spaced $\sim 700 \mu \mathrm{m}$ apart (Fig. 8). 


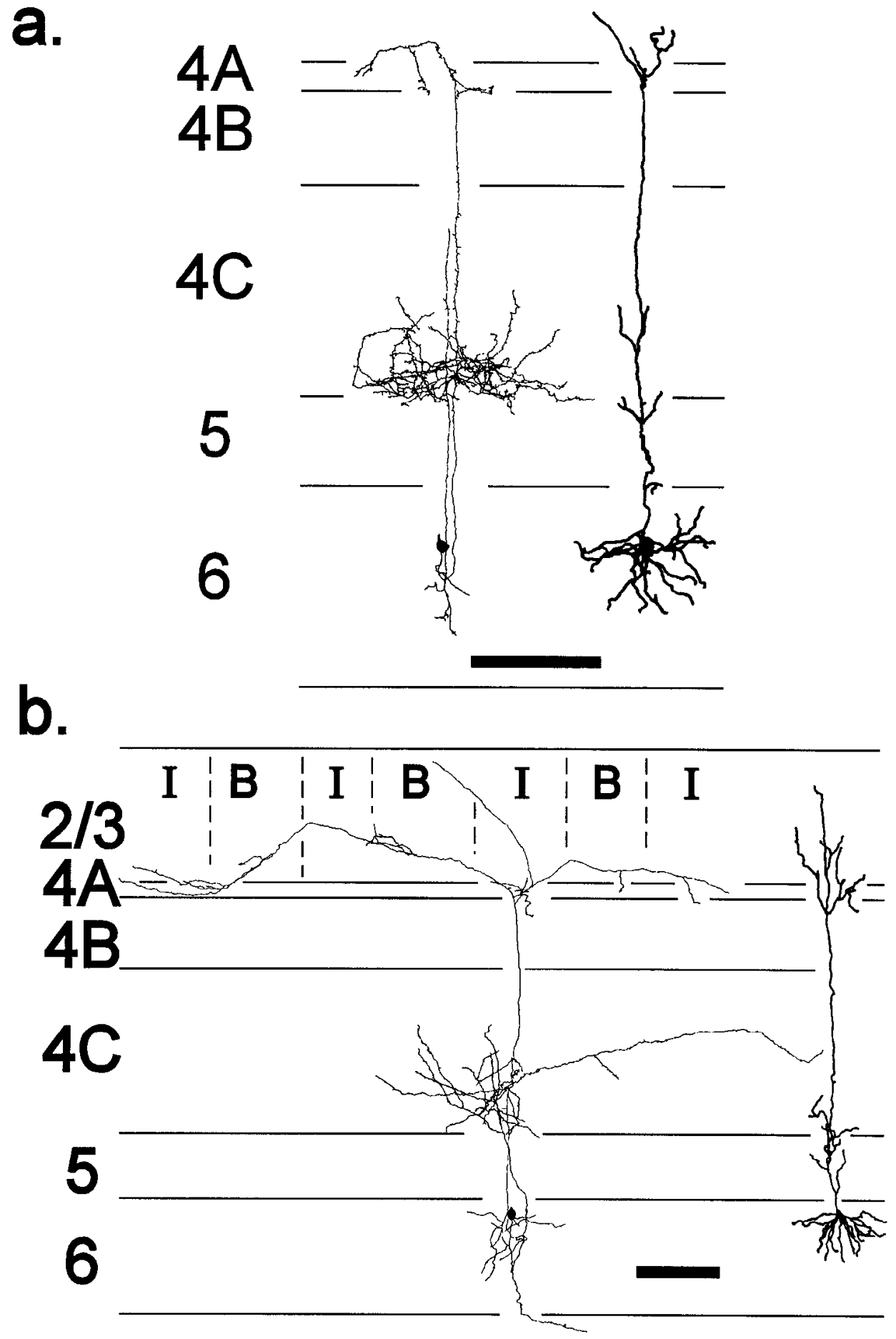

Figure 4. Camera lucida reconstructions of type I $\beta$ A neurons. Both neurons $(a, b)$ project axonal branches predominantly to layers $4 \mathrm{C} \beta(4 C)$ and $4 A$ and, therefore, belong to the type I $\beta A$ (see Results). Both neurons also have axonal branches in their layer of origin (layer 6 ). The neuron shown in $b$ has its cell body in superficial layer 6 , whereas the soma of the neuron in $a$ is closer to the middle of layer 6 . The cell shown in $b$ is a projection neuron. It has axonal branches in layer $2 / 3$ that have no apparent specificity for blobs or interblobs. [Vertical dashed lines in $b$ indicate transitions between blob $(B)$ and interblob $(I)$ compartments in layer $2 / 3$.] For both cells $(a, b)$, basal dendrites are in layer 6 and the apical dendrite branches in layers 5A (5), $4 \mathrm{C} \beta(4 C), 4 A$, and $3 \mathrm{~B}(2 / 3)$. The neuron shown in $b$ also has two apical dendritic branches in layer $5 \mathrm{~B}$, which is unusual for class I neurons. A photograph of the neuron in $a$ is shown in Figure 1c. See previous figures for other conventions. Scale bars, $200 \mu \mathrm{m}$.

In addition to apical and basal dendrites in layer 6, type IIA cells have apical dendritic branches throughout layer 5 or in $5 \mathrm{~B}$ (Figs. 7, 8). The apical dendrites extend to varying levels of layer 4 and occasionally extend to layer $2 / 3$, but only rarely branch above layer $5 \mathrm{~A}$ (Fig. $8 b$ ). Their somata can be found throughout the depth of layer 6 (Figs. 10, 11, Table 2). Seven out of 24 project to the white matter (Table 2). Unlike class I projection neurons, the type IIA projection neurons have cell bodies located toward the middle of layer 6 (Fig. 11).

As we have noted, we could not easily sort type IIA cells into distinct categories without making arbitrary distinctions. One possible exception is a neuron with a dense axonal projection in layer
4A (Fig. 7a). The axonal branches of this cell within layer 4A are clearly focused on the regions beneath interblobs. However, we have only recognized one neuron with this morphology.

\section{Type IIB}

We labeled six cells in the bottom of layer 6 that have a distinctive dendritic morphology and project axons heavily to layer 4B (Fig. $9 a, b)$. They also project to both the blobs and interblobs throughout the depth of layer $2 / 3$. Five out of six cells also project axons to layers 5 and 6 (see Fig. $9 b$ for counterexample); these cells rarely have axonal branches in layer $4 \mathrm{C}$ (see Fig. $9 b$ ). The lateral extent of these neurons is greatest in layers 2-4B and is between 


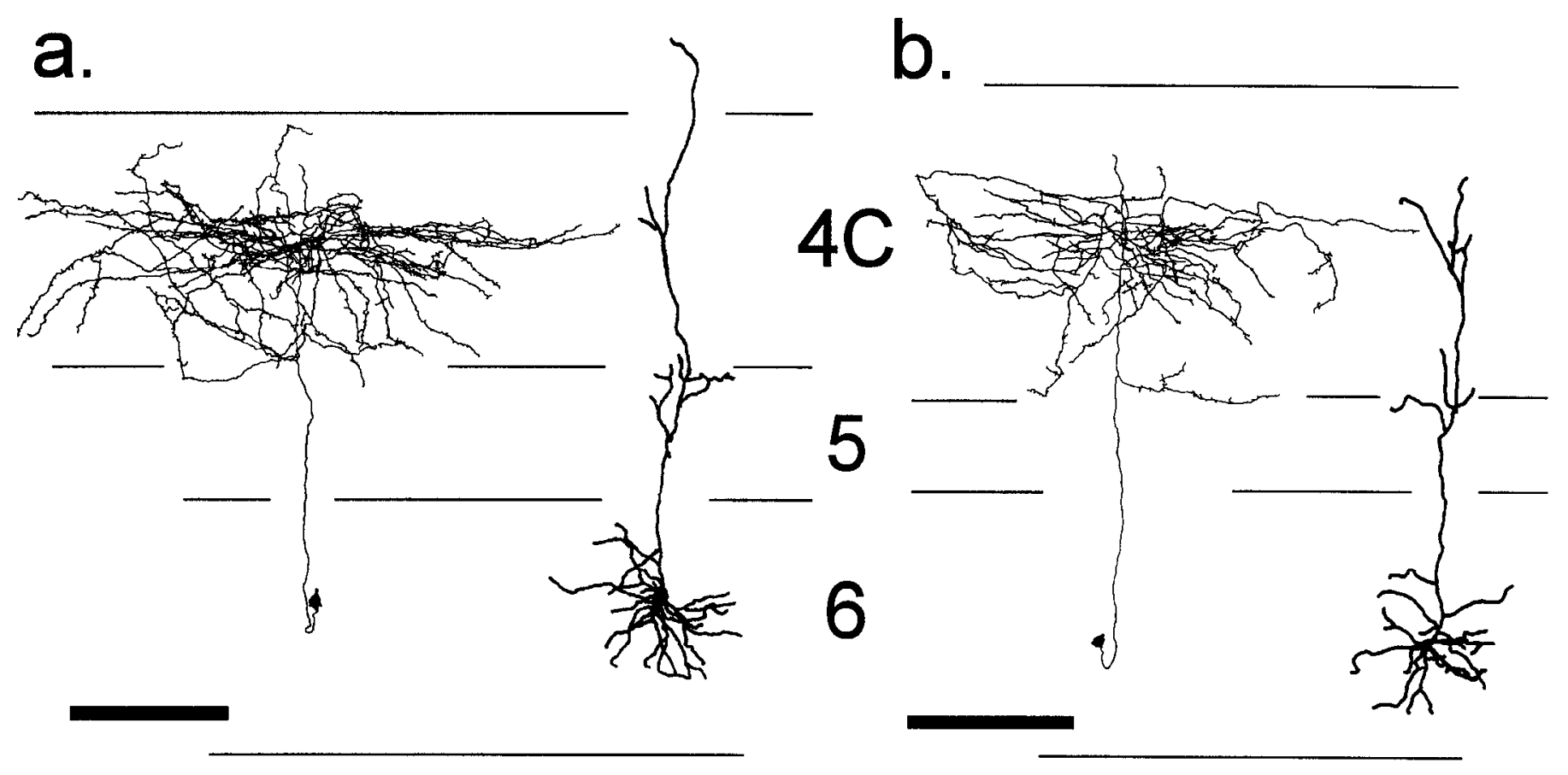

Figure 5. Camera lucida reconstructions of type Im neurons. The layers are identified by number in the space between the two drawings. Neurons shown in $a$ and $b$ have their soma in the middle of layer 6 . They have their densest network of axonal branches in the middle of $4 C$. They do not project to their own layer (6) or to the white matter. The apical dendrites of both cells branch in layer 5A (5) and in the middle of layer $4 C$. See previous figurcs for conventions. Scale bars, $200 \mu \mathrm{m}$.

1 and $2 \mathrm{~mm}$. Type IIB dendritic arbors do not extend above layer 5. Instead, the apical dendrite gives rise to numerous oblique branches throughout layer 5. These cells are deep in layer 6 (Fig. 10 , Table 2) and do not send an axonal branch into the white matter (Table 2).

\section{DISCUSSION}

\section{Summary}

Layer 6 pyramidal neurons in macaque V1 make up a diverse population that can be separated into two classes and several types within these classes (see Fig. 12 for summary). Class I neurons have dense axonal arbors in layer $4 \mathrm{C}$ and lack dendritic branches in layer $5 \mathrm{~B}$, whereas the axonal arbors of class II neurons are focused on layers other than $4 \mathrm{C}$ and they have extensive dendritic arbors in layer 5B.

Type I $\alpha$ neurons have axonal and dendritic arbors that are specific for layer $4 \mathrm{C} \alpha$. Type I $\beta$ axonal arbors are specific for layer $4 \mathrm{C} \beta$, and their dendritic arbors are specific for $4 \mathrm{C} \beta$ and sometimes $4 \mathrm{~A}$. Type I $\beta A$ axonal and dendritic arbors are specific for layers $4 \mathrm{C} \beta$ and $4 \mathrm{~A}$. Type Im neurons have axonal and sometimes dendritic branches specific for the middle third of layer 4C (not the edges). Type IC neurons project axons throughout the depth of layer $4 \mathrm{C}$ and to layer 4A. The lateral spread of axonal arbors within layer $4 \mathrm{C}$ is about twice as cxtensive for type I $\alpha$ neurons than for the remaining four class I types (up to $2 \mathrm{~mm}$ vs up to $1 \mathrm{~mm}$ ).

Class II is subdivided into two types, type IIA and type IIB. Type IIA neurons can project axons to any cortical layer, but most project predominantly to the infragranular layers. Projections within layer 6 can be long and clustered. Type IIB neurons have dense axonal projections to layers $2-4 \mathrm{~B}, 5$, and 6 , but avoid layer $4 \mathrm{C}$. They have extensive dendritic branches in layer 5 but no higher. Although most class II neurons project axons to layer $2 / 3$, there is no evidence for selectivity for $\mathrm{CO}$ blobs versus interblobs in this layer.

Most layer 6 pyramids are nonprojection neurons. Only a subset of types $\mathrm{I} \beta, \mathrm{I} \beta \mathrm{A}, \mathrm{IC}$, and IIA projects to the white matter. All type $\mathrm{I} \alpha$, Im, and IIB neurons in our sample lack projections to the white matter.

\section{Technical considerations}

We are confident that all of the axonal and dendritic processes of neurons in our sample were detected, except those extending beyond the plane of the parent brain slice. Thus, we have no doubt that all of the projections we have observed exist and arise from the cells we identified. We cannot rule out the possibility that additional projections or cell types also exist. For example, we have not encountered a Meynert cell, probably because of their low density (perhaps $25 \mathrm{cells} / \mathrm{mm}^{2}$; Winfield et al., 1981). We also cannot rulc out sampling biases because, for example, certain cell types might be more difficult to record from.

It is important to note that the neurons in our sample are from young postnatal monkeys. We feel that their morphologies represent those in adults. First, 23 of 58 neurons in our sample are from animals $>8$ months old, and all animals were at least 2 months old. Because laminar specificity of axonal arbors, ocular dominance columns, and specificity of circuitry for $\mathrm{CO}$ blobs all develop prenatally in macaque monkeys (Lund et al., 1977; Callaway, 1993; Horton and Hocking, 1995), it is unlikely that there are dramatic changes in laminar specificity after the eighth month. Second, maturation would be expected to result in increased specificity of local circuits. However, we observe a high degree of specificity even in the youngest cells. Finally, although our sample comes from animals ranging in age from 2 to 9 months, each 


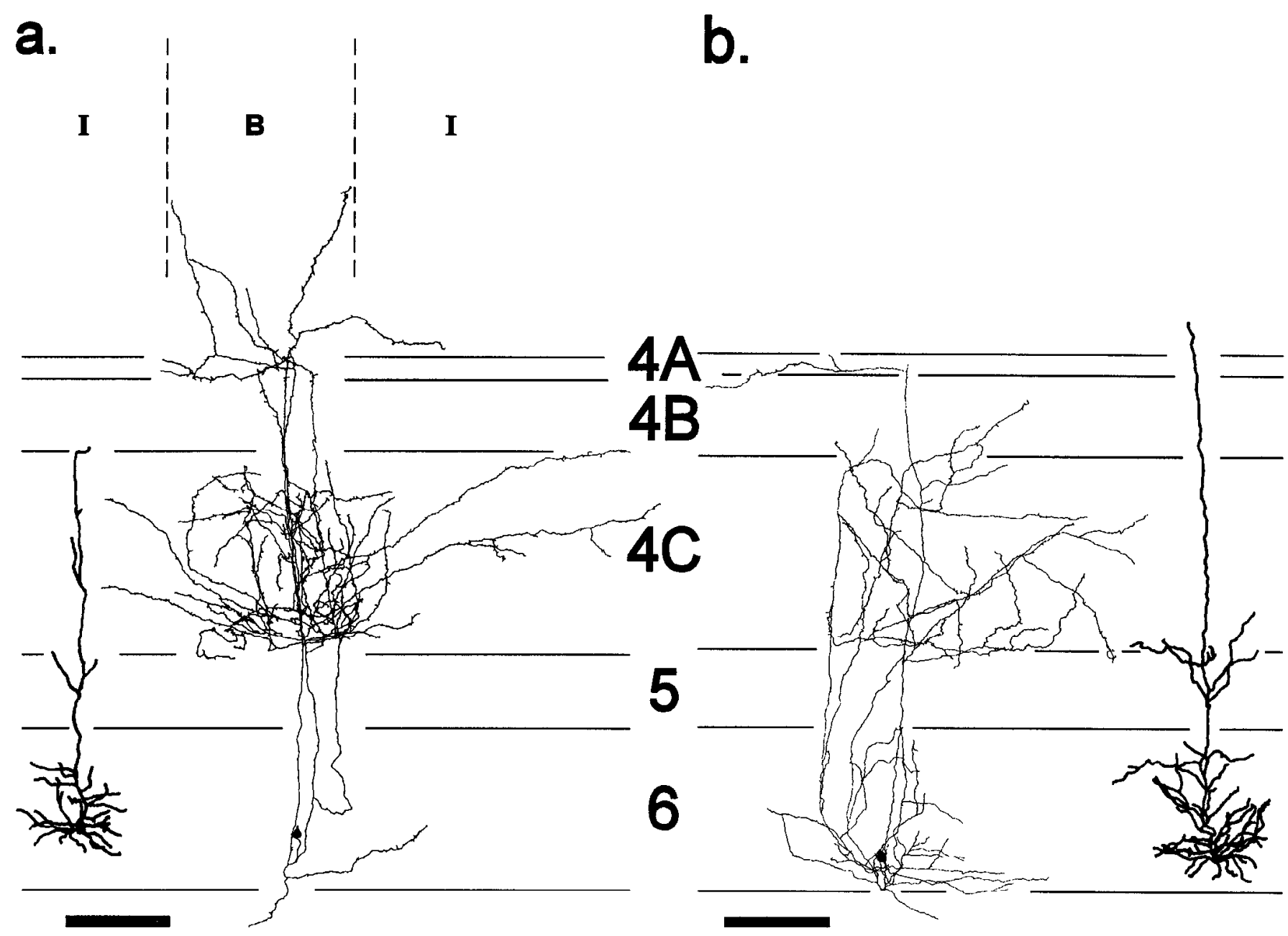

Figure 6. Camera lucida reconstructions of type IC neurons. These neurons $(a, b)$ project dense axonal branches throughout layer $4 C$ and, therefore, belong to the type IC. They also project to layers $4 A$ and 6 . The neuron in $a$ also projects to layer $3 \mathrm{~B}$ (not shown), predominantly but not exclusively to the blob compartment situated directly above its cell body. Neurons shown in $a$ and $b$ have their cell body deep in layer $\sigma$, and they are projection neurons. Both neurons have basal dendrites in layer 6 and an apical dendrite that extends through layer $4 C$ and branches in layers 6 and $5 \mathrm{~A}$ (5). Cell $a$ also has apical dendritic branches in layer $4 C$. See previous figures for conventions. Scale bars, $200 \mu \mathrm{m}$.

neuronal type, except Im, was observed in both 2- to 3-month-old and 8- to 9-month-old animals (type Im was observed only in the two oldest animals; see Table 1). There are no apparent differences between these age groups in the degree of specificity of axonal arbors or any other characteristics of the neurons. Such invariance would not be expected over this span of $>5$ months if the neurons were undergoing developmental changes in the parameters we analyzed.

\section{Class I neurons}

About half of the layer 6 pyramidal neurons are class I neurons. These have dense axonal projections predominantly to layer $4 \mathrm{C}$. This is not surprising because both Golgi studies and extracellular tracer injections have revealed strong projections from layer 6 to this layer (Lund and Boothe, 1975; Lund et al., 1977; Fitzpatrick et al., 1985; Yoshioka et al., 1994).

Our observations suggest that class I neurons belong to distinct types such as those we have defined. The distinct differences in laminar specificity of axonal arbors within layer $4 \mathrm{C}$ allowed unambiguous classification of all 28 class I neurons; there are no cells with intermediate levels of specificity. Also, none of the types was defined merely to accommodate cells that did not fit into another group; at least three neurons are included in each type. Laminar specificity of axonal arbors is also correlated with other distinguishing features that are consistent within each population. In particular, each type has a distinct pattern of dendritic arborization and a distinct depth distribution. Nevertheless, we cannot rule out the possibility that intermediatc forms or other cell types exist but were not detected in our sample.

Within class $I$, we find three types of neurons that project specifically to either layer $4 \mathrm{C} \alpha$ or $4 \mathrm{C} \beta$ : types $\mathrm{I} \alpha, \mathrm{I} \beta$, and $\mathrm{I} \beta \mathrm{A}$. These layers are dominated by a single functional stream [magnocellular (M) or parvocellular (P); see Lund, 1988], and these cell types are therefore likely to be involved in streamspecific computations. Two other cell types, Im and IC, have axonal arbors that are not restricted to $4 \mathrm{C} \alpha$ or $4 \mathrm{C} \beta$. These neurons could mediate cross-talk between the $M$ and $P$ streams. Furthermore, type Im cells, which project specifically 


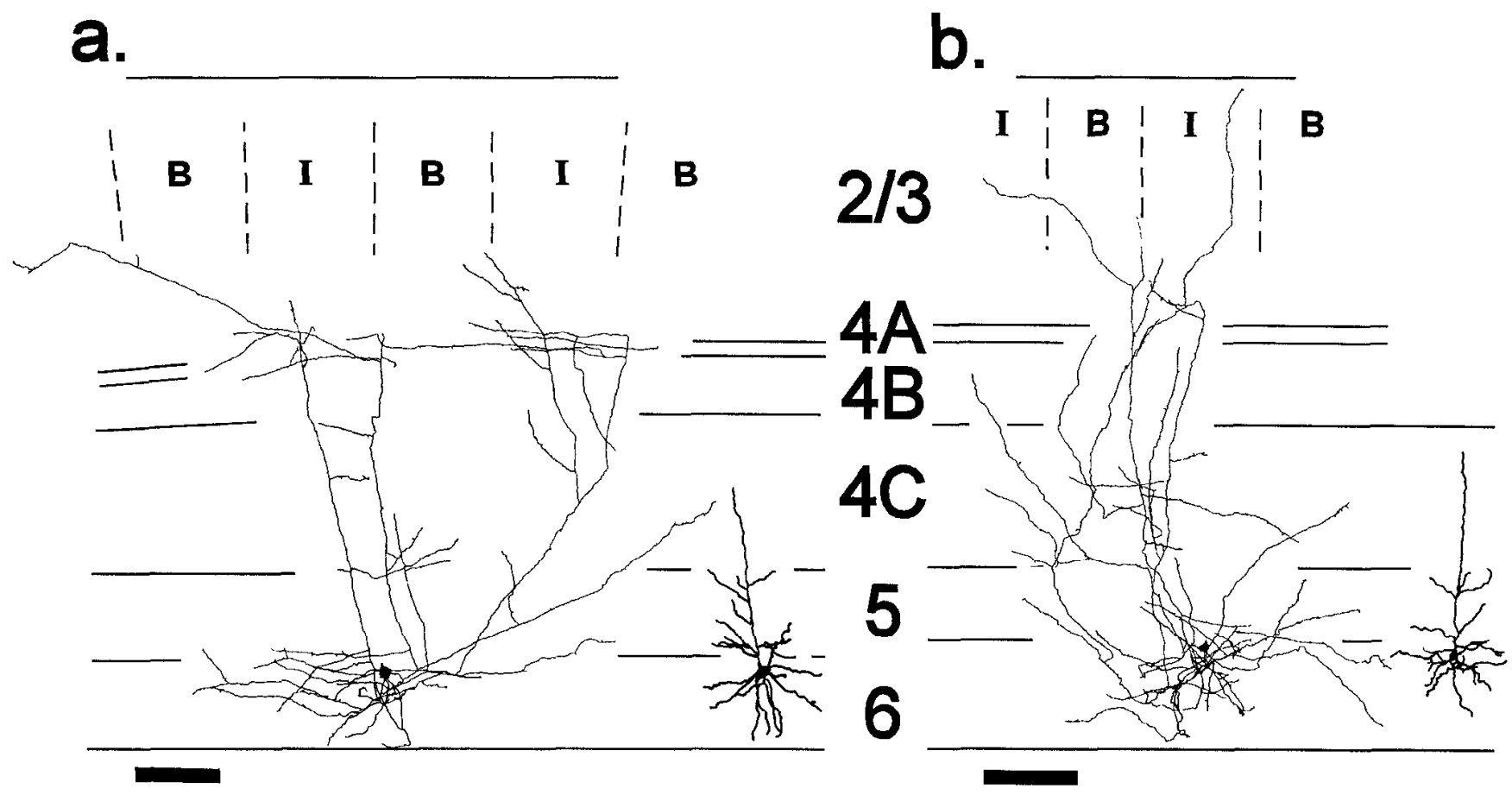

Figure 7. Camera lucida reconstructions of type IIA neurons. These neurons have widespread axonal projections that do not specifically target layer $4 C$ and apical dendritic branches in layer 5B (5); they therefore belong to class II. They lack the features characteristic of type IIB neurons and, therefore, belong to type IIA (see Results). Both cells have heavy axonal projections to layer 6 and weaker projections throughout the cortical depth. The neuron illustrated in $a$ shows a particular affinity for layer $4 A$, where clusters of axons are located directly beneath interblobs. The cell bodies of both neurons are superficial in layer 6 . Like a majority of type IIA neurons, these are nonprojection neurons. The apical dendrites of these cells extend into layer $4 C$ and (unlike class I cells) branch throughout layer 5. See previous figures for conventions. Scale bars, $200 \mu \mathrm{m}$.

to mid-layer $4 \mathrm{C}$, might reflect the specialization of mid-4C for computations requiring convergent $\mathrm{M}$ and $\mathrm{P}$ input (Mates and Lund, 1983; Blasdel and Fitzpatrick, 1984; Yoshioka et al., 1994).

Each of the five types of class I neuron has a distinct laminar pattern of dendritic arborization that is strikingly similar to the pattern of axonal arborization. This observation suggests that class I neurons provide input onto neurons with which they share common sources of geniculate input. In addition, these neurons might receive input from the same neurons to which they project. Thus, they appear to provide feedback to layer 4C. The functional significance of this is considered below.

Based on Golgi-stained prenatal material, Lund et al. (1977) defined four types of layer 6 pyramidal neurons ( 8 including "variants"). These would all be characterized as class I neurons using our criteria. However, only two of our five types of class I neurons, types $\mathrm{I} \alpha$ and I $\beta \mathrm{A}$, clearly correspond to types described in these studies. Five of the eight types identified by Lund et al. (1977) are not present in our postnatal sample, suggesting that they represent immature forms, that there were errors in laminar identification (see Lund, 1988), or that they exist postnatally but were not detected in our sample. Our types $I \beta$ and Im do not correspond to any of those described by Lund et al. (1977), nor do the class II neurons. A type I $\beta$ A neuron has been filled intracellularly by Anderson et al. (1993).

Previous studies did not reveal which types project to extrinsic targets or their laminar distributions. With intracellular labeling, however, we identified a clear relationship between the depth of class I cells in layer 6 and whether they project to the white matter.
Because LGN-projecting neurons and class I projection neurons are both found primarily in the upper and lower thirds of layer 6 (Fitzpatrick et al., 1994), we suggest that class I projection neurons target the LGN. The type I $\alpha$ and Im cells in our sample do not project to the white matter and are found in midlayer 6 . The three type IC cells in our sample all project to the white matter and have somata deep in layer 6 . For the type $\mathrm{I} \beta$ and I $\beta$ A cells, superficial and deep cells tend to project to the white matter, whereas cells in midlayer 6 are usually nonprojecting. Thus, the LGN is likely to be targeted by types I $\beta, I \beta A$, and IC, but may not receive input from types $\mathrm{I} \alpha$ or $\mathrm{Im}$.

Furthermore, neurons projecting to magnocellular layers of the LGN are found almost exclusively at the bottom of layer 6 (Fitzpatrick et al., 1994). These could be type I $\beta$ or IC neurons, but we suggest that type IC neurons are more likely because type $\mathrm{I} \beta$ cells restrict their local projections to P-recipient layer $4 \mathrm{C} \beta$. Neurons projecting to parvocellular LGN are found at the top and bottom of layer 6 (Fitzpatrick et al., 1994). We suggest that type $\mathrm{I} \beta \mathrm{A}$ projection neurons, found only at the top of layer 6 , along with superficial type $\mathrm{I} \beta$ neurons, make up the superficial neurons targeting parvocellular LGN. Type I $\beta$ and/or IC could make up the deeper population. Finally, it is possible that the type IC neurons (and perhaps also the deep type $\mathrm{I} \beta$ cells) project to both $M$ and $P$ layers of the LGN.

\section{Class II neurons}

Class II is better described as a continuum of cells with varying axonal and dendritic morphologies than as a series of distinct types. Only type IIB neurons compose a distinct type of class II 


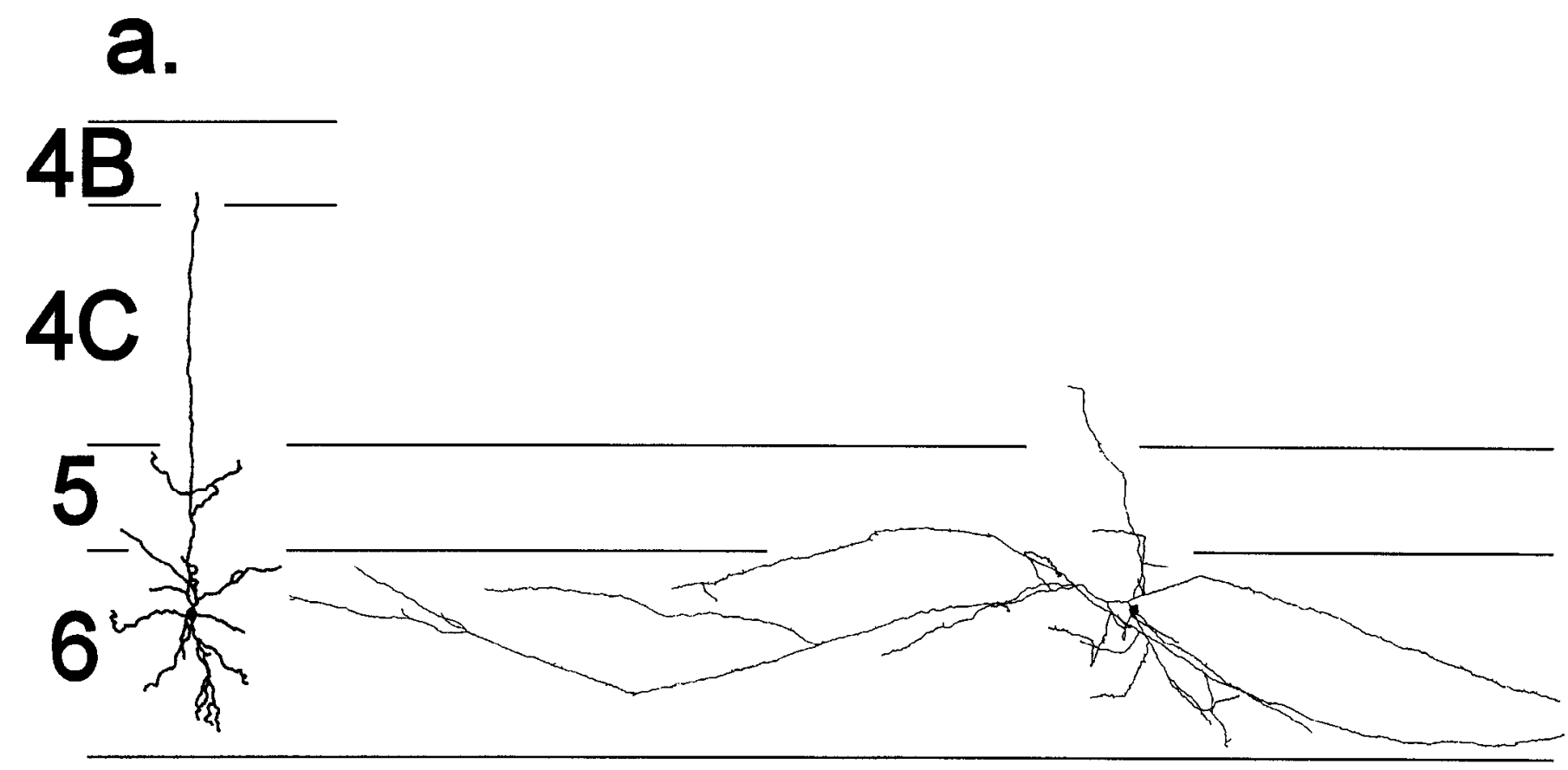

\section{b.}

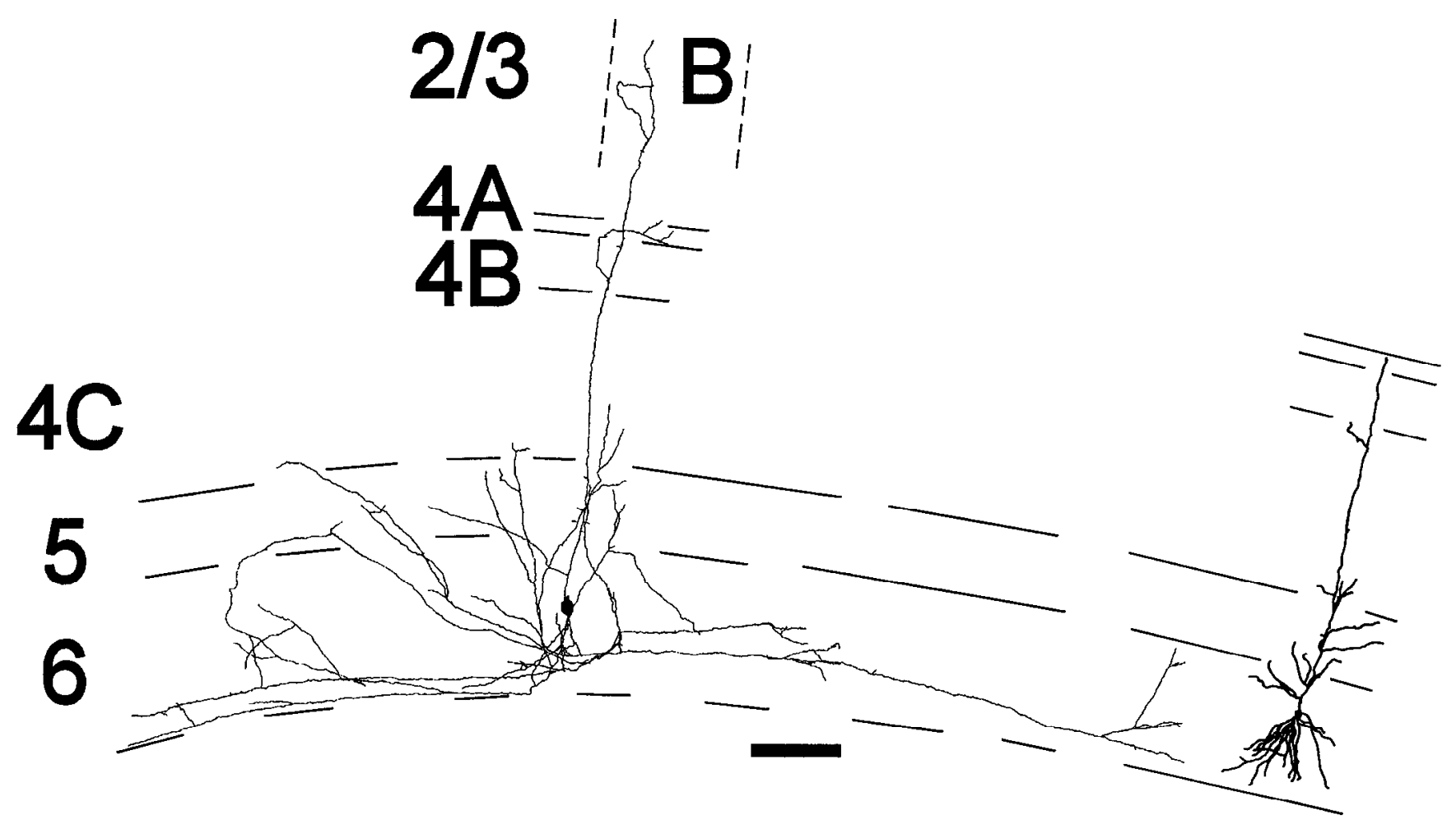

Figure 8. Camera lucida reconstructions of type IIA neurons. Both neurons $(a, b)$ have long, patchy axonal projections in layer 6 . The neuron illustrated in $b$ also has a strong axonal projection to layer 5 and weaker projections to layer $4 A$ and to a blob in layer $2 / 3$. The cell body of the neuron shown in $a$ is in superficial layer 6 , whereas the one belonging to the neuron shown in $b$ is closer to the middle of layer 6 . Neither neuron projects to the white matter. The apical dendrite of neuron $a$ extends to layer $4 B$ and branches in layer 5 . The apical dendrite in $b$ extends to layer $4 A$ and branches once in layer $4 \mathrm{C} a$ $(4 C)$ and throughout layer 5. See previous figures for conventions. Scale bars, $200 \mu \mathrm{m}$. 
Table 1. Distribution of cell types and their depths

\begin{tabular}{|c|c|c|c|c|c|c|c|c|c|c|c|c|}
\hline \multirow[b]{2}{*}{ Name } & \multirow[b]{2}{*}{ Age } & \multirow[b]{2}{*}{ Layer 6 cells } & \multicolumn{3}{|c|}{ Depth distribution } & \multicolumn{7}{|c|}{ Type distribution } \\
\hline & & & Superficial & Middle & Deep & $\mathbf{I} \alpha$ & $\mathrm{I} \beta$ & $\mathrm{I} \beta \mathrm{A}$ & $\mathrm{Im}$ & IC & IIA & IIB \\
\hline B13 & 2 months & 1 & 0 & 0 & 1 & 0 & 0 & 0 & 0 & 0 & 1 & 0 \\
\hline B12 & 3 months & 2 & 0 & 1 & 1 & 1 & 1 & 0 & 0 & 0 & 0 & 0 \\
\hline B16 & 3 months & 10 & 0 & 5 & 5 & 1 & 1 & 1 & 0 & 1 & 4 & 2 \\
\hline B19 & 3.5 months & 7 & 5 & 1 & 1 & 0 & 0 & 1 & 0 & 0 & 6 & 0 \\
\hline B17 & 4.5 months & 12 & 2 & 4 & 6 & 3 & 0 & 1 & 0 & 1 & 6 & 1 \\
\hline B14 & 5 months & 3 & 0 & 0 & 3 & 0 & 1 & 0 & 0 & 0 & 1 & 1 \\
\hline B8 & 8 months & 18 & 8 & 6 & 4 & 1 & 4 & 3 & 3 & 1 & 4 & 2 \\
\hline B11 & 9 months & 5 & 3 & 2 & 0 & 0 & 1 & 1 & 1 & 0 & 2 & 0 \\
\hline
\end{tabular}

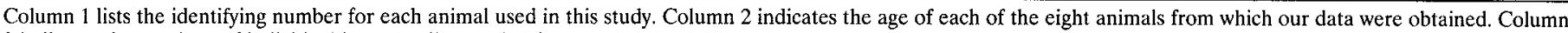

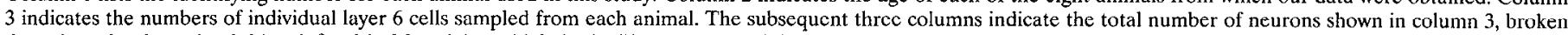

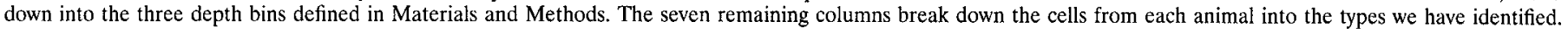

cell. The remaining cells (type IIA) vary considerably in their morphology.

Many class II neurons project axons quite far laterally in layer 6 , in agreement with the observations of Blasdel et al. (1985). A majority of class II neurons also project to layer 5 , consistent with retrograde labeling reported by Fitzpatrick et al. (1985). Class II cells do not project strongly to layer $4 \mathrm{C}$, and some avoid this layer altogether. This was surprising because previous studies have not revealed such neurons. Also, class II cells can have sparse or even dense projections in layer 4B. This projection was not detected by

\begin{tabular}{|c|c|c|c|c|c|c|c|}
\hline Ccll typc & Namc & Depth & WM & Cell type & Name & Depth & WM \\
\hline \multirow[t]{7}{*}{$\mathrm{I} \alpha$} & & & & IIA & & & \\
\hline & B17.15.2.1 & Middle & No & & B8.22.1.4 & Superficial & No \\
\hline & B8.24.3.1 & Middle & No & & B19.15.1.1 & Superficial & No \\
\hline & B12.14.2.2 & Middle & No & & B8 822.2 .1 & Superficial & No \\
\hline & B16.15.1.2 & Middle & No & & B19.12.2.2 & Superficial & No \\
\hline & B17.13.2.1 & Deep & No & & B17.16.1.2 & Superficial & No \\
\hline & B17.11.1.1 & Deep & No & & B11.14.3.1 & Superficial & No \\
\hline \multirow[t]{10}{*}{$\mathrm{I} \beta$} & & & & & B8.13.1.1 & Superficial & Yes \\
\hline & B8.22.1.1 & Superficial & No & & B19.14.2.2 & Superficial & No \\
\hline & B11.4.3.1 & Superficial & Yes & & B19.13.1.1 & Superficial & No \\
\hline & B8.27.3.2 & Superficial & Yes & & B11.14.4.1 & Middlc & No \\
\hline & B8.27.2.1 & Middle & No & & B17.12.2.2 & Middle & No \\
\hline & B16.12.2.1 & Middle & No & & B16.11.2.2 & Middle & No \\
\hline & B14.12.3.1 & Deep & No & & B19.14.2.3 & Middle & No \\
\hline & B12.12.2.1 & Deep & No & & B8.11.2.1 & Middle & Yes \\
\hline & B8.25.2.1 & Deep & Yes & & B16.11.1.1 & Middle & Yes \\
\hline & & & & & B17.15.1.2 & Middle & No \\
\hline \multirow[t]{7}{*}{$\mathrm{I} \beta \mathrm{A}$} & B19.12.2.1 & Superficial & Yes & & B17.12.1.1 & Middle & No \\
\hline & B8.21.3.2 & Superficial & Yes & & $\mathrm{B} 16.16 .1 .2$ & Deep & Yes \\
\hline & B8.13.1.2 & Sipperficial & Yes & & B16.16.1.1 & Deep & No \\
\hline & B17.16.1.1 & Superficial & No & & B14.12.1.1 & Deep & Yes \\
\hline & B11.15.3.1 & Superficial & No & & B19.14.2.1 & Deep & No \\
\hline & B8.26.1.2 & Middle & No & & B17.14.2.1 & Deep & Yes \\
\hline & B16.12.2.3 & Middle & No & & B13.12.1.1 & Deep & No \\
\hline \multirow[t]{5}{*}{ Im } & & & & & B17.11.2.1 & Deep & Yes \\
\hline & B8.27.3.1 & Superficial & No & & & & \\
\hline & B8.11.2.2 & Middle & No & IIB & B16.15.1.1 & Deep & No \\
\hline & B11.12.4.1 & Middle & No & & B16.16.2.1 & Deep & No \\
\hline & B8 28.3 .1 & Middle & No & & B14.11.4.1 & Deep & No \\
\hline \multirow[t]{4}{*}{ IC } & & & & & B8.21.3.1 & Deep & No \\
\hline & B8.26.1.1 & Deep & Yes & & B8.2.2.1 & Deep & No \\
\hline & B16.15.2.1 & Deep & Yes & & B17.15.1.1 & Deep & No \\
\hline & $\mathrm{B} 17.12 .2 .1$ & Deep & Yes & & & & \\
\hline
\end{tabular}

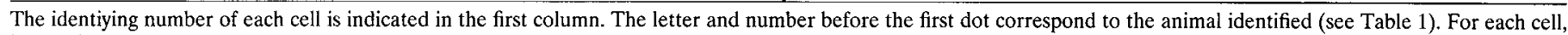
its depth and whether it projects to the white matter (WM) are also indicated. 

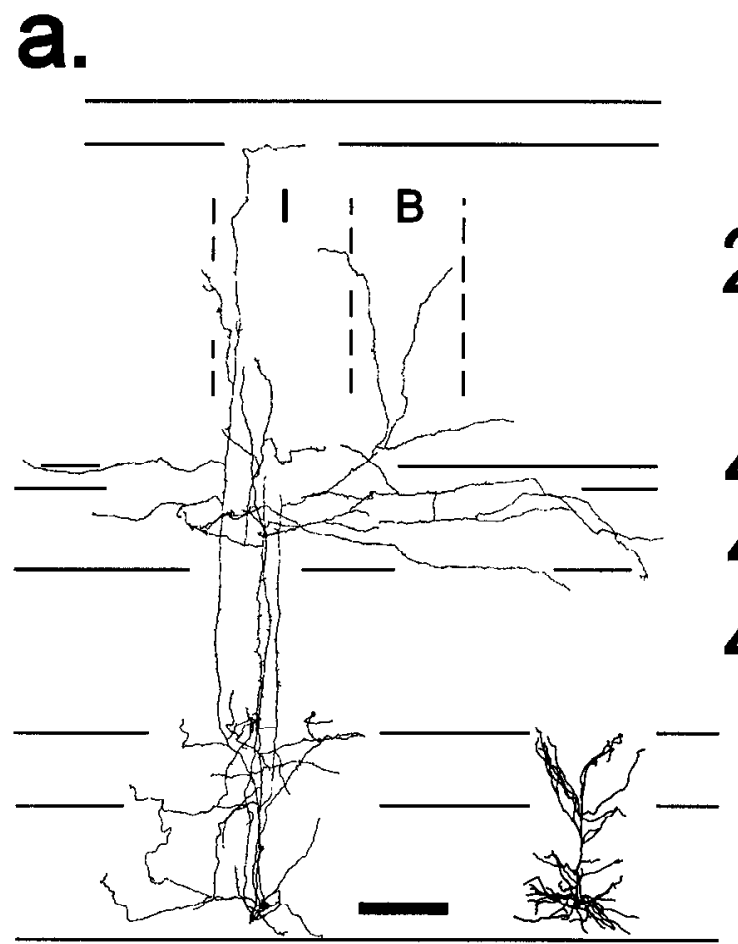

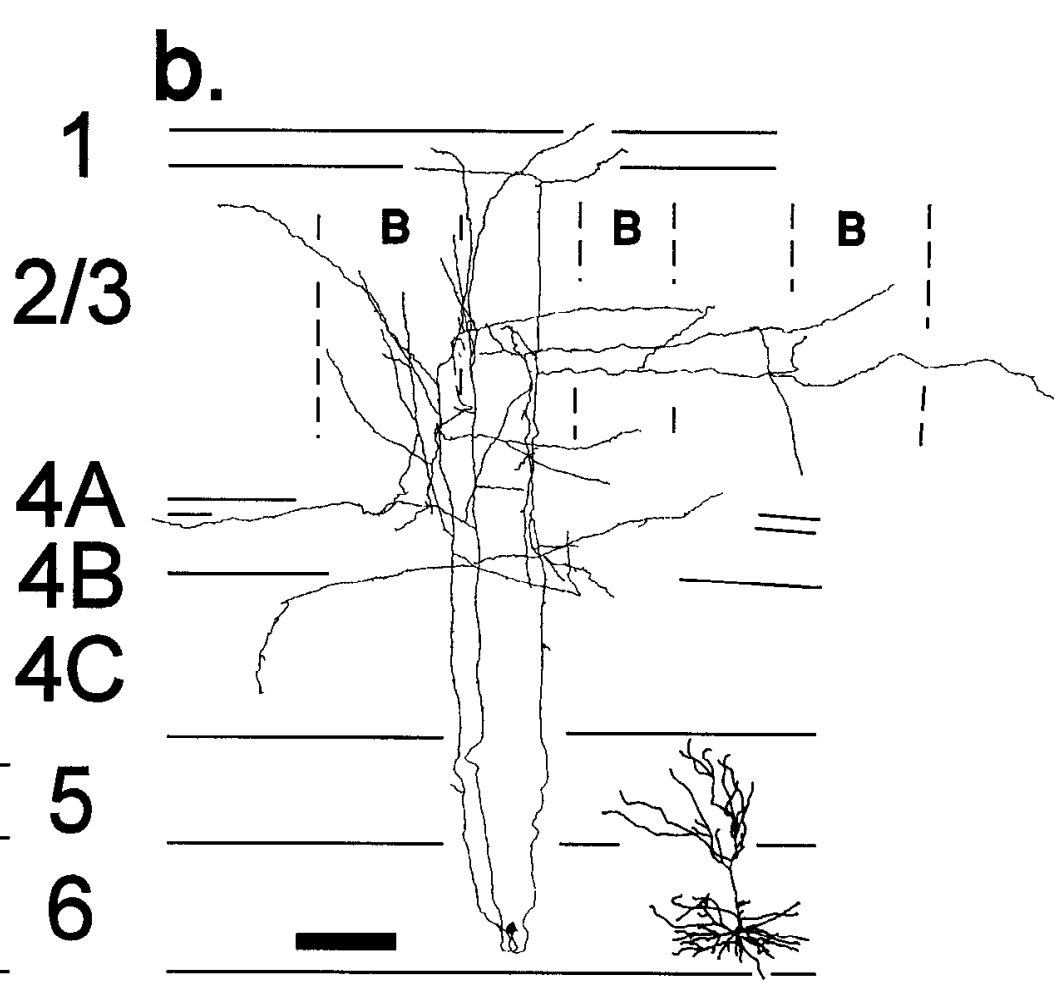

Figure 9. Camera lucida reconstructions of type IIB neurons. These neurons have widespread axonal projections that avoid layer $4 C$. Within layer 4 , axonal branching occurs primarily in layer $4 B$. Axons of both neurons also project to blobs and interblobs of layer $2 / 3$ and reach layer 1 . The cell in $a$ also projects to layers 5 and 6 . The apical dendrites of these cells do not extend past layer 5 where they branch profusely. The somata of these cells are in deep layer 6 . These are nonprojection neurons. See previous figures for conventions. Scale bars, $200 \mu \mathrm{m}$.

Blasdel et al. (1985), but retrograde labeling in layer 6 after layer 4B injections (Yoshioka et al., 1994) suggested its existence. Most class II cells project to layer $2 / 3$, with no specificity for blob or interblob regions. They, along with some type I $\beta A$ and IC neurons, are probably responsible for layer $2 / 3$ projections observed after anterograde tracer injections in layer 6 (Blasdel et al., 1985).
Type IIA cells can be found throughout the depth of layer 6 , but the $27 \%(7 / 26)$ that project to the white matter are located predomimantly in midlayer 6 . Thus, they probably do not target the LGN (see Fitzpatrick et al., 1994). Because claustral projecting cells are found in midlayer 6 in the cat (LeVay and Sherk, 1981), we suggest this is the likely target of type IIA projection
Figure 10. Depth distribution of the different types of layer 6 neurons. $a$, Bar graph of the number of cells belonging to different types versus the depth of the cell body in layer 6 (superficial, medium, or deep). $b$, Bar graph of the percentage of cells of each type found at a particular depth in layer 6 . For both graphs, each type of layer 6 neuron is represented by a different fill pattern (see legend on the right).

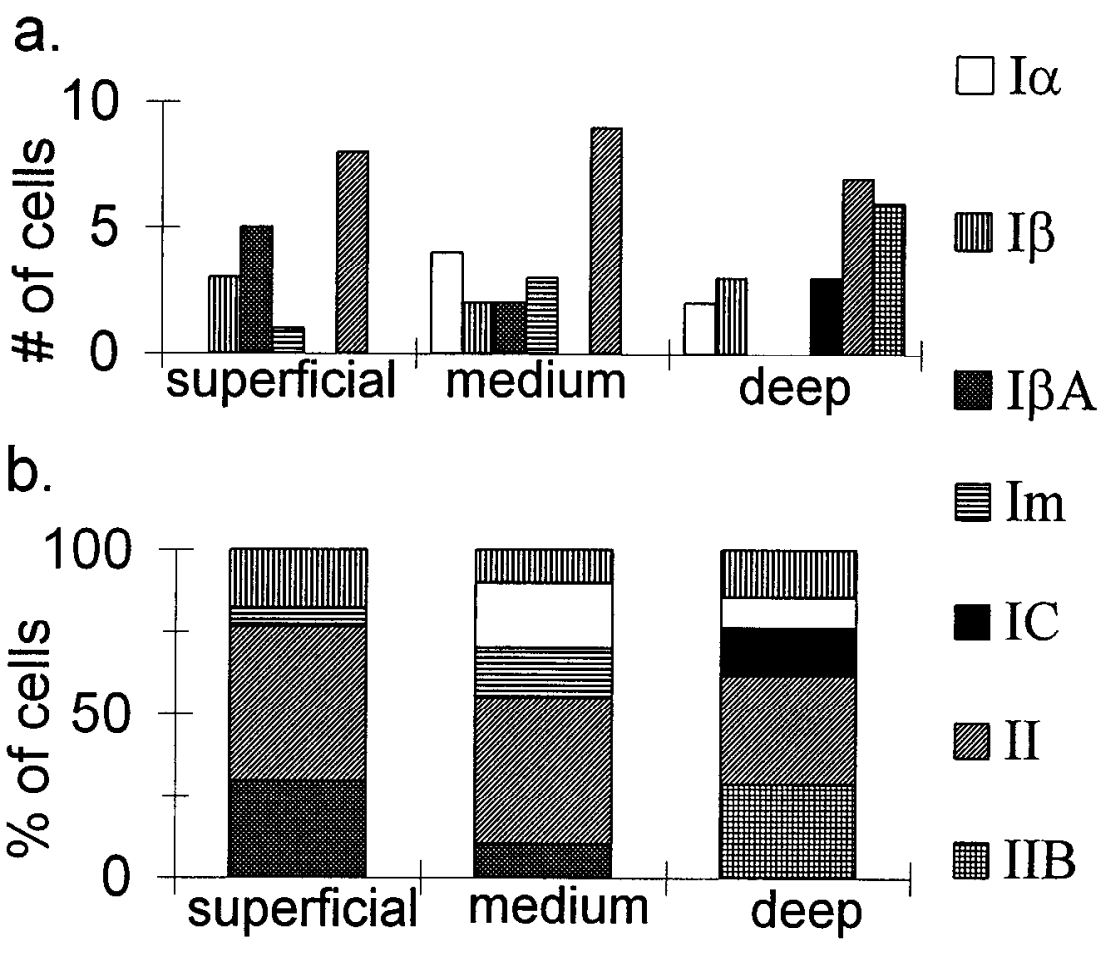




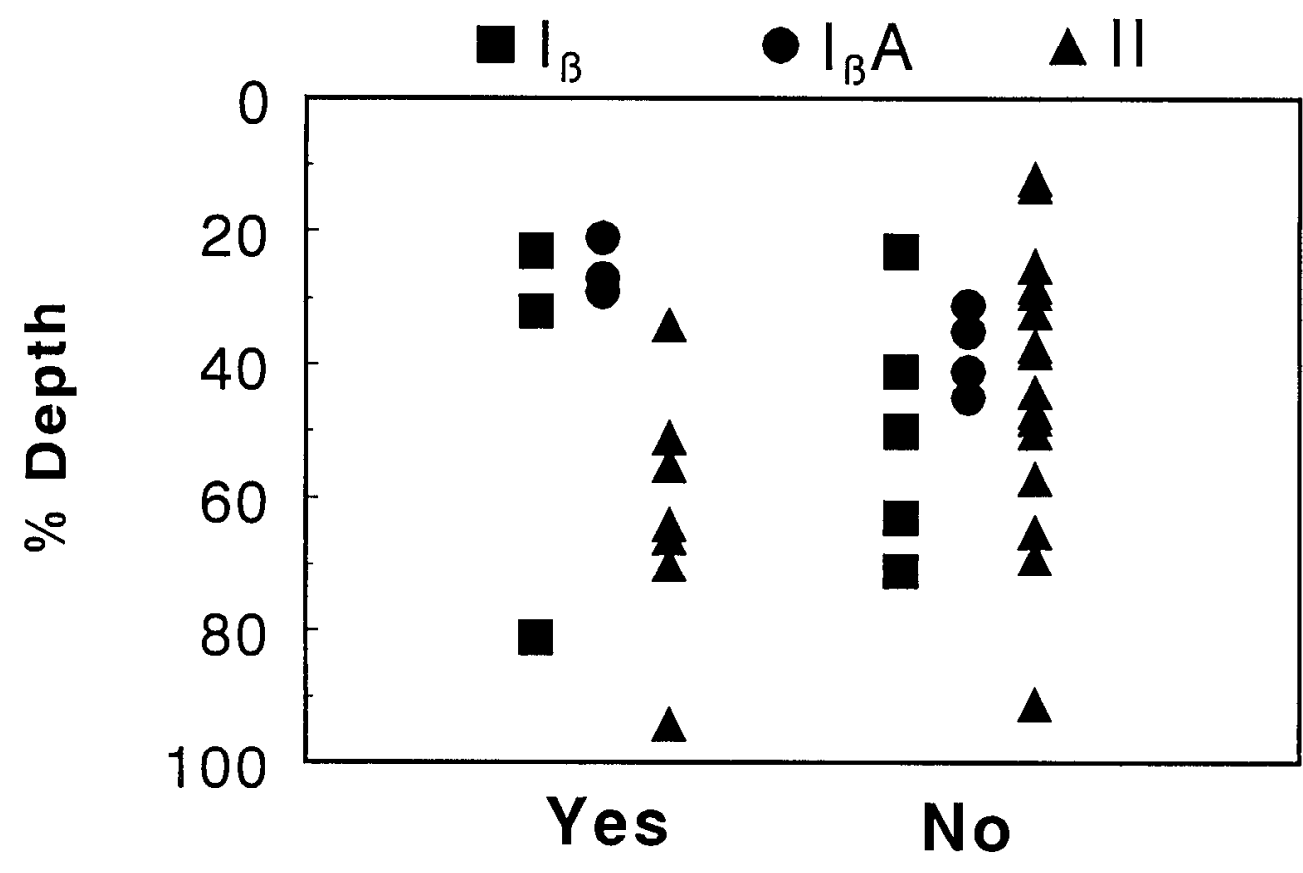

Projection to white matter
Figure 11. Depth distribution of projection and nonprojection neurons belonging to types containing both categories. This scatter plot shows the depths of individual layer 6 cells of types $I \beta$ (squares), I $\beta$ A (circles), and IIA (triangles) grouped according to whether they project to the white matter (Yes) or not $(\mathrm{No})$. Types $\mathrm{I} \alpha, \mathrm{Im}$, and IIB are not included because none project to the white matter. Type IC cells are not included because all three in our sample project to the white matter and are located deep in layer 6 . For type $\mathrm{I} \beta$, the projection neurons are superficial or deep, whereas nonprojection neurons are predominantly in midlayer 6 . For type $I \beta A$, the most supcrficial neurons also project to the white matter, whereas slightly deeper cells toward the middle of layer 6 do not. For type IIA, projection neurons are predominantly in the middle of layer 6 , but nonprojection cells are found at all depths. neurons. This possibility is supported by the similarity between type IIA neurons and claustral-projecting neurons in the cat; both project axons predominantly to the infragranular layers (Katz, 1987).

\section{Functional roles of different neuron types}

The differences between neuronal types suggest that they play different roles in shaping the response properties of V1 neurons. In considering our results, we have made a number of observations that suggest that layer 6 neurons in primates are specialized for functions that have been proposed based on results from cats (Hubel and Wiesel, 1965; Sherk and LeVay, 1983; Bolz and Gilbert, 1986; Sillito et al., 1994). We have therefore adapted these to the macaque monkey.

\section{Role of class I cells}

We propose that class I neurons contribute to the emergence of orientation selectivity by synchronizing the activity of layer $4 \mathrm{C}$ cells with circular receptive fields. This is analogous to the role proposed for the projection from layer 6 to the LGN in the cat (Sillito et al., 1994). In support of this notion, Sillito et al. have reported (Society for Neuroscience Meeting, 1994) that synchronous activation of layer $4 \mathrm{C}$ neurons is generated with long bars of light but not spots. Furthermore, inactivation of infragranular layers reduces the orientation selectivity of superficial neurons in Galago monkeys (Allison et al., 1995). Because the only orientation-selective neurons (those activated by bars but not spots) in V1 that project strongly to layer $4 \mathrm{C}$ are class I, layer 6 neurons, we propose that they are responsible for generation of synchrony in layer $4 \mathrm{C}$.

If in the monkey the required synchrony can be generated in layer $4 \mathrm{C}$, a strong corticogeniculate projection comparable with that in the cat may not be required. Consistent with this possibility, Fitzpatrick et al. (1994) estimate that only $13 \%$ of layer 6 neurons project to the LGN. Nine of our 58 cells are class I projection neurons. If we assume that these all project to the LGN and that type IIA projection neurons do not (see above), we obtain a value of $16 \%$.

This hypothesis leads to testable predictions. Class I neurons should have short receptive fields (see below), and the positive feedback role implies that they should connect to spiny ncurons. Also, axonal projections within layer $4 \mathrm{C}$ might be elongated along a topographic axis that corresponds to the orientation selectivity of the layer 6 neurons.

\section{Role of class II cells}

We hypothesize that class II neurons are involved in endstopping, either via a cortico-claustral-cortical loop (Sherk and LeVay, 1983) or via local circuits (Hubel and Wiesel, 1965; Bolz and Gilbert, 1986). Regardless of how the effect is mediated, each model requires involvement of layer 6 neurons with long receptive fields. We suggest that class II neurons are likely to have long receptive fields. These could result from input from long-distance projections originating in layers 5 and 2-4B (Blasdel et al., 1985) onto the extensive dendritic branches of class II neurons in layer 5B [see Bolz and Gilbert (1989) for discussion of the generation of long receptive fields]. This hypothesis is also supported by the likelihood that type IIA neurons project to the claustrum (see above) and the observation that claustral-projecting cells in the cat have long receptive fields (Grieve and Sillito, 1995). Also, the intrinsic projections of class II neurons are focused on layers containing orientation selective neurons; connections to such cells are important for the local circuit version of the hypothesis (Bolz and Gilbert, 1986) (see also below).

The hypothesis that class II neurons are involved in end-stopping leads to testable predictions. First, class II cells 


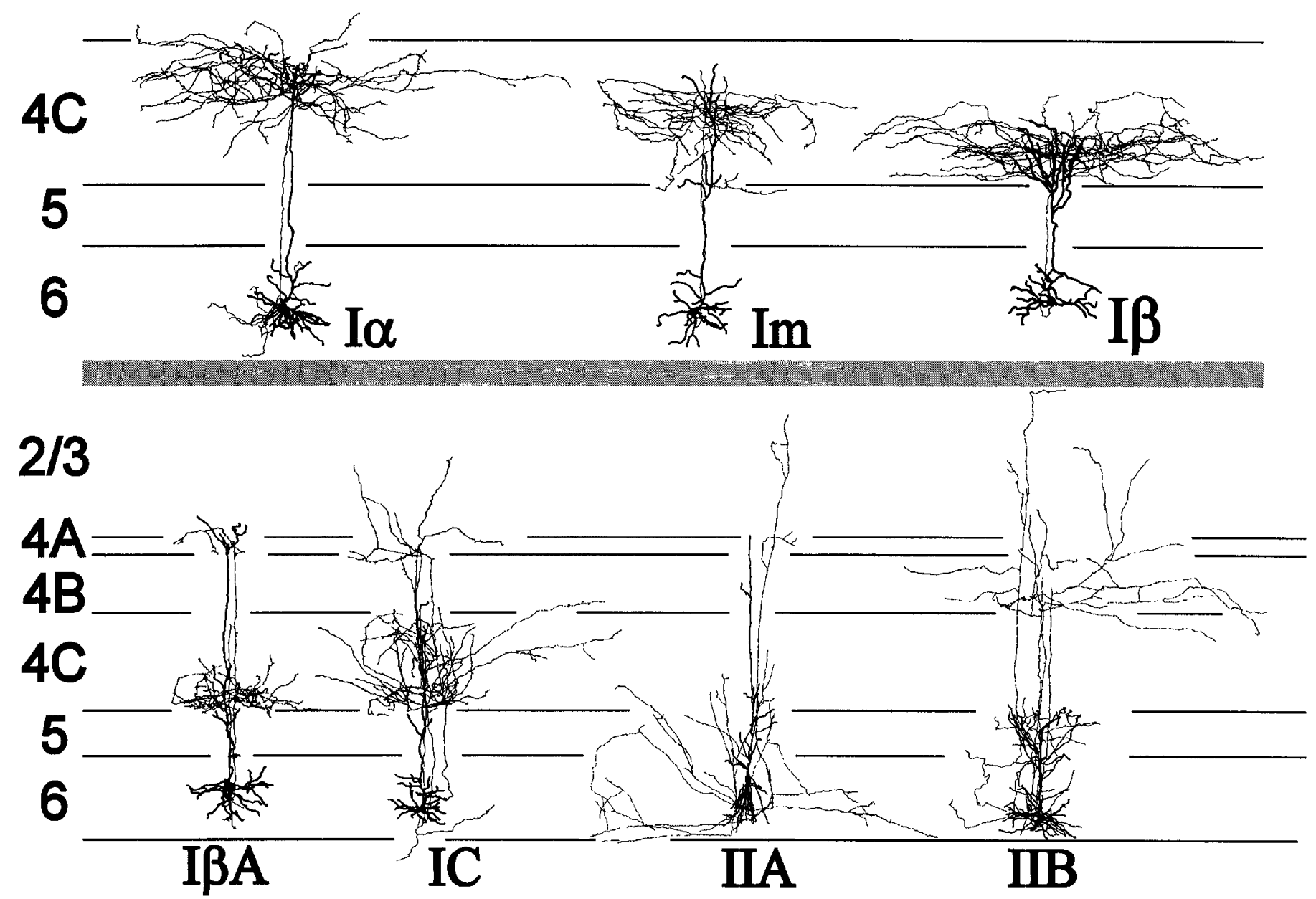

Figure 12. Summary diagram of the seven types of layer 6 neurons identified. The neuronal sketches are modified (simplified) camera lucida drawings. The type of each cell is indicated beneath or at the bottom right of each sketch. Layers are indicated by numbering at the left side of the figure. The top of the figure shows schematic representations of the three types of class I neurons that do not project above layer $4 C$. The bottom shows schematics of the four types of layer 6 neurons that project axons more superficially. The top and bottom of the figure are separated by a thick gray line, which also delimits the boundary between layer 6 and the white matter for the top portion, and the boundary between layer $2 / 3$ and layer 1 for the bottom portion. Dendritic arbors (bold lines) are indicated at their actual positions, superimposed over the axonal arbors (finer lines).

should have long receptive fields. Second, they should project to the claustrum. Although our results suggest this is the case, more direct approaches could be used. Finally, the local projections of class II neurons should be onto inhibitory interneurons. This could be tested by electron microscopic analyses of the neurons that receive input from class II cells, or by functional analyses of the sources of input to inhibitory interneurons using photostimulation (Callaway and Katz, 1993; Dalva and Katz, 1994).

\section{REFERENCES}

Allison JD, Casagrande VA, Bonds AB (1995) The influence of input from the lower cortical layers on the orientation tuning of upper layer V1 cells in a primate. Vis Neurosci 12:309-320.

Anderson JC, Martin KAC, Whitteridge D (1993) Form, function, and intracortical projections of neurons in the striate cortex of the monkey Macacus nemestrinus. Cereb Cortex 3:412-420.

Blanton MG, Lo Turco JJ, Kriegstein AR (1989) Whole cell recording from neurons in slices of reptilian and mammalian cerebral cortex. J Neurosci Methods 30:203-210.

Blasdel GG, Fitzpatrick D (1984) Physiological organization of layer 4 in macaque striate cortex. J Neurosci 4:880-895.
Blasdel GG, Lund JS, Fitzpatrick D (1985) Intrinsic connections of macaque striate cortex: axonal projections of cells outside lamina $4 \mathrm{C}$. J Neurosci 5:3350-3369.

Bolz J, Gilbert CD (1986) Generation of end-inhibition in the visual cortex via interlaminar connections. Nature 320:362-365.

Bolz J, Gilbert CD (1989) The role of horizontal connections in gencrating long receptive fields in the cat visual cortex. Eur J Neurosci 1:263-268.

Callaway EM (1993) Organization of functional stream specific local circuits in the primary visual cortex of newborn macaque monkeys. Soc Neurosci Abstr 19:240.

Callaway EM, Katz LC (1992) Development of axonal arbors of layer 4 spiny neurons in cat striate cortex. J Neurosci 12:570-582.

Callaway EM, Katz LC (1993) Photostimulation using caged glutamate reveals functional circuitry in living brain slices. Proc Natl Acad Sci USA 90:7661-7665.

Dalva MB, Katz LC (1994) Rearrangements of synaptic connections in visual cortex revealed by laser photostimulation. Science 265:255-258.

Fitzpatrick D, Lund JS, Blasdel GG (1985) Intrinsic connections of macaque striate cortex: afferent and efferent connections of lamina $4 \mathrm{C}$. J Neurosci 5:3329-3349.

Fitzpatrick D, Usrey WM, Schofield BR, Einstein G (1994) The sublaminar organization of corticogeniculate neurons in layer 6 of macaque striate cortex. Vis Neurosci 11:307-315. 
Grieve KL, Sillito AM (1995) Differential properties of cells in the feline primary visual cortex providing corticofugal feedback to the lateral geniculate nucleus and visual claustrum. J Neurosci 15:4868-4874.

Horton JC (1984) Cytochrome oxidase patches: a new cytoarchitectonic feature of monkey visual cortex. Philos Trans R Soc Lond Biol 304: $199-253$.

Horton JC, Hocking DR (1995) Newborn monkeys have well segregated ocular dominance columns organized in an adult-like mosaic prior to visual experience. Soc Neurosci Abstr 21:1284.

Hubel DH, Wiesel TN (1965) Receptive fields and functional architecture in two nonstriate visual areas (18 and 19) of the cat. J Neurophysiol $28: 229-289$

Katz LC (1987) Local circuitry of identified projection neurons in cat visual cortex brain slices. J Neurosci 7:1223-1249.

Katz LC, Gilbert CD, Wiesel TN (1989) Local circuits and ocular dominance columns in monkcy striate cortcx. $J$ Ncurosci 9:1389-1399.

Lachica EA, Beck PD, Casagrande VA (1992) Parallel pathways in macaque monkey striate cortex: anatomically defined columns in layer III. Proc Natl Acad Sci USA 89:3566-3570.

LeVay S, Sherk H (1981) The visual claustrum of the cat. I. Structure and connections. J Neurosci 319:141-158.

Lund JS (1973) Organization of neurons in the visual cortex, Area 17, of the monkey (Macaca mulatta). J Comp Neurol 147:455-496.

Lund JS. (1987) Local circuit neurons of macaque monkey striate cortex. I. Neurons of laminae 4C and 5A. J Comp Neurol 257:60-92.
Lund JS (1988) Anatomical organization of macaque monkey striate visual cortcx. Annu Rev Neurosci 11:253-288.

Lund JS, Boothe RG (1975) Interlaminar connections and pyramidal neuron organisation in the visual cortex, area 17 , of the macaque monkey. J Comp Neurol 159:305-334.

Lund JS, Boothe RG, Lund RD (1977) Development of neurons in the visual cortex of the monkey (Macaca nemestrina): a Golgi study from fetal day 127 to postnatal maturity. J Comp Neurol 176: 149-188.

Mates SL, Lund JS (1983) Neuronal composition and development in lamina 4C of monkey striate cortex. J Comp Neurol 221:60-90.

Sherk H, LeVay S (1983) Contribution of the cortico-claustral loop to receptive field properties in area 17 of the cat. J Neurosci 3:2121-2127.

Sillito AM, Jones HE, Gerstein GL, West DC (1994) Feature-linked synchronization of thalamic relay cell firing induced by feedback from the visual cortex. Nature 369:479-482.

Valverde $\mathbf{F}$ (1985) The organizing principles of the primary visual cortex in the monkey. In: Cerebral cortex, Vol 3 (Peters A, Jones EG, eds), pp 207-257. New York: Plenum.

Winfield DA, Rivera-Dominguez M, Powell TPS (1981) The number and distribution of Meynert cells in area 17 of the macaque monkey. Proc R Soc Lond [Biol] 213:27-40.

Yoshioka T, Levitt JB, Lund JS (1994) Independence and merger of thalamocortical channels within macaque monkey primary visual cortex: anatomy of interlaminar projections. Vis Neurosci 11:467-489. 